\title{
A performance-based fire risk analysis for buildings
}

\author{
António B. Leiras ${ }^{1}$ J João Paulo C. Rodrigues ${ }^{1,2} \cdot$ Brian J. Meacham $^{3}$
}

Received: 26 April 2021 / Accepted: 15 November 2021/Published online: 11 December 2021

(c) The Author(s), under exclusive licence to Springer Nature Switzerland AG 2021

\begin{abstract}
Fire safety can be defined as the requirements that cumulatively guarantee the absence of conditions for fire ignition and also eliminate or minimize the effects of the fire on people and property. Based on this premise, we can assume that a fire risk assessment methodology is more effective as more components contributing to fire safety are integrated in the analysis process. In this paper a new fire risk assessment methodology is proposed, based in a holistic approach analyzes of the potential of failure of each of the critical components, that compete differently for the overall performance of the fire safety of the building. This methodology attempts to respond to the problems of the current risk analysis methodologies regarding their applicability — with identical reliability—in different types of buildings and fire scenarios. In order to reduce the level of uncertainty, as much as possible, the method uses a redundant fire risk estimation process. In one analysis dimension, the model uses the parameters of probability, severity and exposure of fire for valuing the risk in function of the failure potential of performance analysis indicators considered critical in relation to the variables of fire prevention and protection. It is compared an actual or potential performance with a standard performance considered as safe. In another dimension of analysis, the method determines the potential of fire growth and spread in function of the existing conditions in the building, to assess whether it is safe for its occupants, until the complete evacuation of the building.
\end{abstract}

Keywords Fire $\cdot$ Building $\cdot$ Risk assessment $\cdot$ Performance based methodology

\section{Introduction}

Fire risk assessment is a process that seeks to determine the likelihood of a fire to outbreak and the consequences of its effects. There are numerous restrictions on the current fire risk analysis methodologies regarding the possibility of using them with the same reliability in the context of multiple fire scenarios. Their use depends usually on the use-type of the building. It can be concluded that all methodologies start from an analytical base to a more or less extended number of components that their authors consider as the more critical to fire safety. The main differences between the methodologies found, are the number of components considered, the relative weighting of the analyzed components,

João Paulo C. Rodrigues

jpaulocr@dec.uc.pt

1 Department of Civil Engineering, FCT, University of Coimbra, Coimbra, Portugal

2 CERIS, Instituto Superior Técnico, University of Lisbon, Lisbon, Portugal

3 Meacham Associates, Shrewsbury, MA 01545, USA the mathematical model used and the way the respective variables are integrated in the fire risk analysis process.

Fire risk analysis methods can be subdivided in four categories: checklists, narrative methods, indexing methods, and probabilistic methods. In general, approaches differ in the technique used to deal with uncertainties arising from variability of fire conditions and the lack of a complete knowledge of fire hazard represented by engineering models or probabilistic data categories [1]. For example, in chemical industry fire risk analysis maybe carry out by one of the following types of analysis (i) qualitative analysis, that describes the quality of the risk by quality parameters, ii) quantitative analysis, that calculates the fire risk quantifying the parameters, where it is possible to make a distinction between a deterministic and probabilistic analysis, being the deterministic analysis focused in the description of the risks in terms of their consequences and the probabilistic analysis focused on the description of the risks based on their frequency and consequences; and iii) semi-quantitative analysis, that uses values quantifying the qualitative data [2-4]. Differences also exist in the bases of the uncertainty and risk quantification, from objective or frequent approaches, that 
rely strictly on statistical data, to subjective approaches, that range from expert judgment to more formal techniques such as the Bayesian methods [5].

As regards to the principles of design, there are fire risk analysis methodologies designed specifically for specific risks [6] and some for general purposes. The event trees, for example, are a general purpose methodology designed specifically for fire risk analysis with relative success in industry. There are more prescriptive methodologies, such as the Gretener's method [6] and some of performance based nature, such as the methodologies developed by Fitzgerald and Meacham [7].

\section{Bases for a new fire risk analysis methodology}

Assuming that fire safety depends on the effectiveness of the fire preventive measures and fire protection means, it can be considered that fire risk is as higher as the potential of failure of these two aspects are. The analysis is settled in two main pillars, the Prevention Index $\left(\mathrm{I}_{\mathrm{PREV}}\right)$ and the Protection Index $\left(\mathrm{I}_{\mathrm{PROT}}\right)$, allowing the determination of the fire safety performance and the consequent fire risk arising from its potential to failure.

Based on this premise, the new Performance-Based Fire Risk Assessment (PEFIRA) methodology is based on a dual fire risk analysis. With a prescriptive approach, the method analyzes in a semi-quantitative way the performance of certain components considered critical for the performance of certain variables, and this performance is compared with a previously established optimized performance. At the same time, with a performance-based approach, the methodology analyzes the behavior of the building in comparison to certain fire scenarios, assessing whether their performance ensures the safety of the occupants until the complete evacuation of the building.

The methodology integrates on its calculation process different Performance Analysis Indicators (PAI) with Performance Critical Areas (PCA) corresponding to Performance Action Domains (PAD) (Fig. 1). In order to use this methodology in different contexts, with the same reliability, each PCA is affected by a weighting factor that is function of the extrinsic fire risk factors and each PAI is affected by a correction factor that is function of the intrinsic fire risk factors. With this procedure it is considered that the model can achieve the suitable application to a broader universe of fire scenarios.

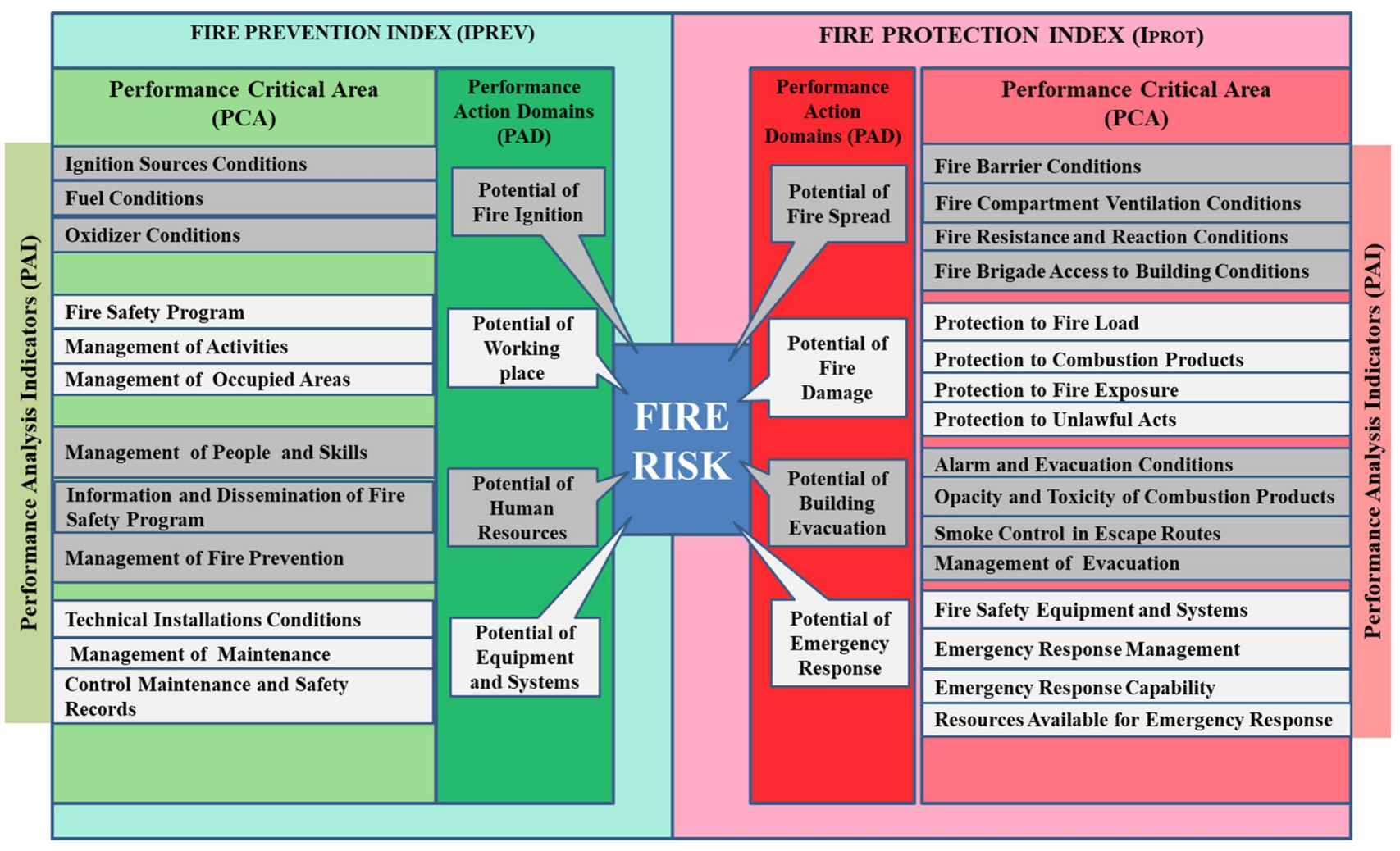

Fig. 1 PEFIRA methodology 
Based on performance analysis indicators (inputs), PEFIRA generates management indicators (outputs) that show the performance of the critical components. This, besides permitting a careful fire risk assessment, it also allows the decision-making process to be widely used in fire safety management of buildings.

Assuming that the expression that best represents the fire risk is the one that integrates the variables related to probability, severity and exposure, PEFIRA methodology uses a three-dimensional estimate of fire risk, in function of the potential of failure of each PAI. For this purpose, it uses a comparative analysis between the real or potential performance of each of these indicators and a standard performance previously defined as Optimized Performance of the Function (OPF).

\section{Fire safety performance analysis process}

To ensure an acceptable level of reliability, regardless the target assessment scenario, the PEFIRA methodology relies on the selection and analysis of 8 PAD, 28 PCA, and 156 PAI with 1300 performance criteria (Fig. 2). PEFIRA uses performance analysis indicators as safety markers, which are analyzed by checklists using a Likert scale methodology that integrates four levels of failure potential (loss of function) classification. In Fig. 3 an example of a PAD checklist for the Potential of Fire Ignition is presented.

To reduce the degree of uncertainty in the model of evaluation, the PAI are classified as first-order or second-order indicators of priority analysis.

\begin{tabular}{|c|}
\hline $\begin{array}{l}\text { Potential of Fire } \\
\text { Ignition }\end{array}$ \\
\hline $\begin{array}{c}\text { Potential of } \\
\text { Working place }\end{array}$ \\
\hline $\begin{array}{l}\text { Potential of } \\
\text { Human } \\
\text { Resource }\end{array}$ \\
\hline $\begin{array}{c}\text { Potential of } \\
\text { Equipment and } \\
\text { systems }\end{array}$ \\
\hline $\begin{array}{c}\text { Potential of Fire } \\
\text { Spread }\end{array}$ \\
\hline $\begin{array}{c}\text { Potential of Fire } \\
\text { Damage }\end{array}$ \\
\hline $\begin{array}{l}\text { Potential of } \\
\text { Building } \\
\text { Evacuation }\end{array}$ \\
\hline $\begin{array}{l}\text { Potential of } \\
\text { Emergency } \\
\text { Response }\end{array}$ \\
\hline
\end{tabular}

8

\begin{tabular}{|l}
\hline Fire Resistance and Reaction conditions \\
\hline Fire Brigade Access to Building Conditions \\
\hline Protection to Fire Load \\
\hline Protection to Combustion Products \\
\hline Protection to Fire Exposure \\
\hline Protection to Unlawful Acts \\
\hline Alarm and Evacuation Conditions \\
\hline Opacity and Toxicity of Combustion Products \\
\hline Smoke Control on Escape Routes \\
\hline Management of Evacuation \\
\hline Fire Safety Equipment and Systems \\
\hline Emergency Response Management \\
\hline Emergency Response Capability \\
\hline Resources Available for Emergency Response \\
\hline
\end{tabular}

Resources Available for Emergency Response

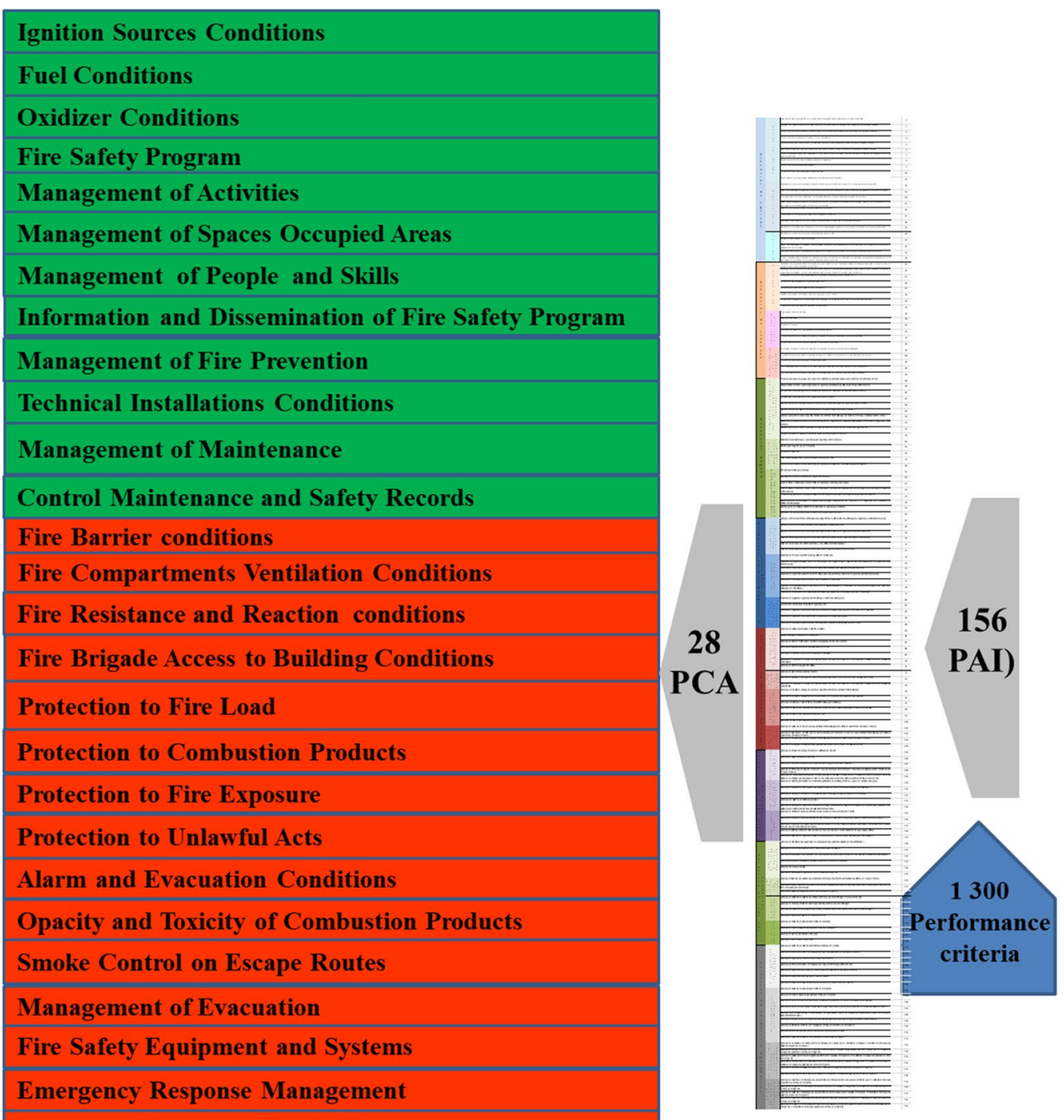

Fig. 2 Fire safety components 


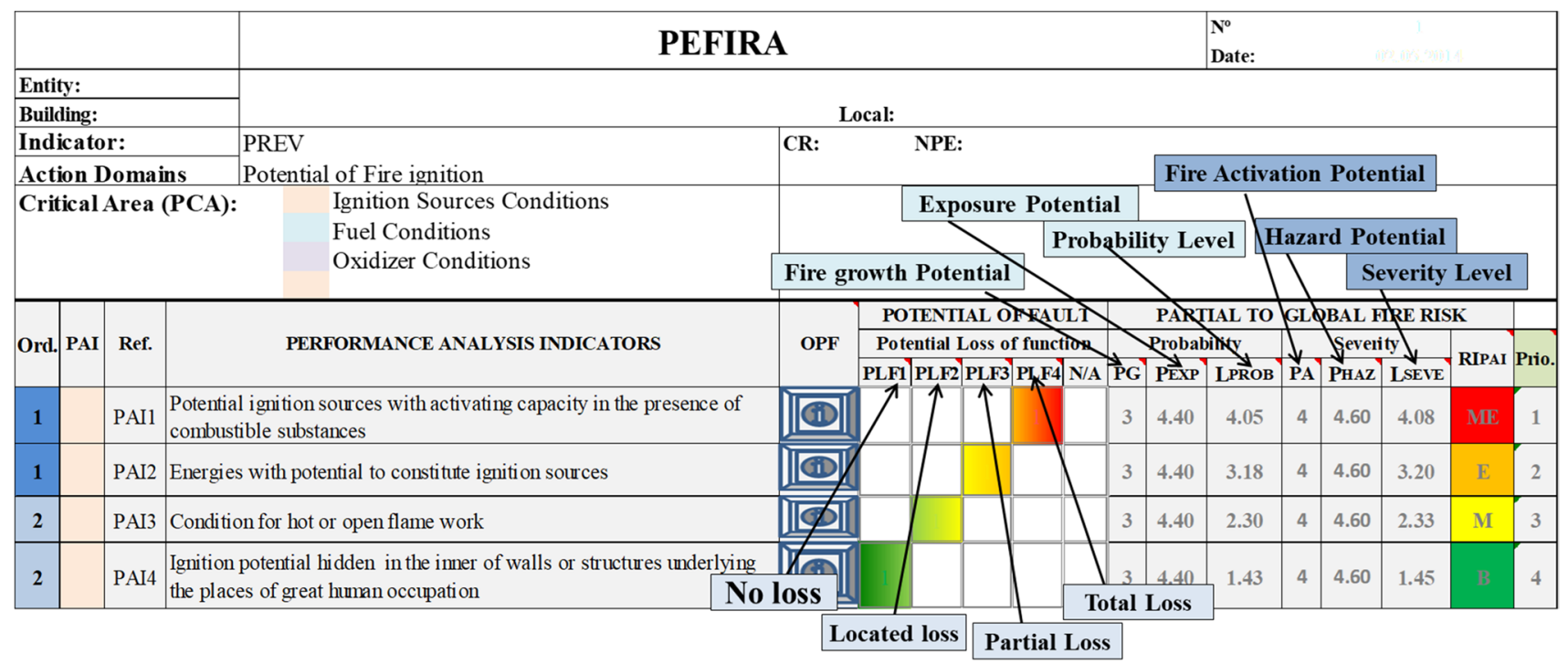

Fig. 3 Checklist sheet

The method begins by estimating fire safety and the consequent fire risk, using only the first order PAI (weighted average of these PAI) and only when the fire risk related to these is smaller than 0.75 , it starts to use the first and second order PAI (weighted average of these PAI). For example, the overall fire risk (weighted average of the $1^{\text {st }}$ and $2^{\text {nd }}$ order PAI) in a building can be 0.4 (maximum 1), but if the value of this risk relatively only to the 1 st order PAI is 0.76 , the PEFIRA considers the overall fire risk of the building as 0.76 and not as 0.4 . This reduces the uncertainty (by risk dilution effect) that tends to increase with the increasing number of variables.

The order of analysis of the PAI is given by the algorithm presented in Fig. 4.

The PEFIRA methodology analyzes the fire safety performance in two dimensions. In one occurs a general analysis in function of a standard performance of reference
Fig. 4 Priority order algorithm in the assessment of the PCA

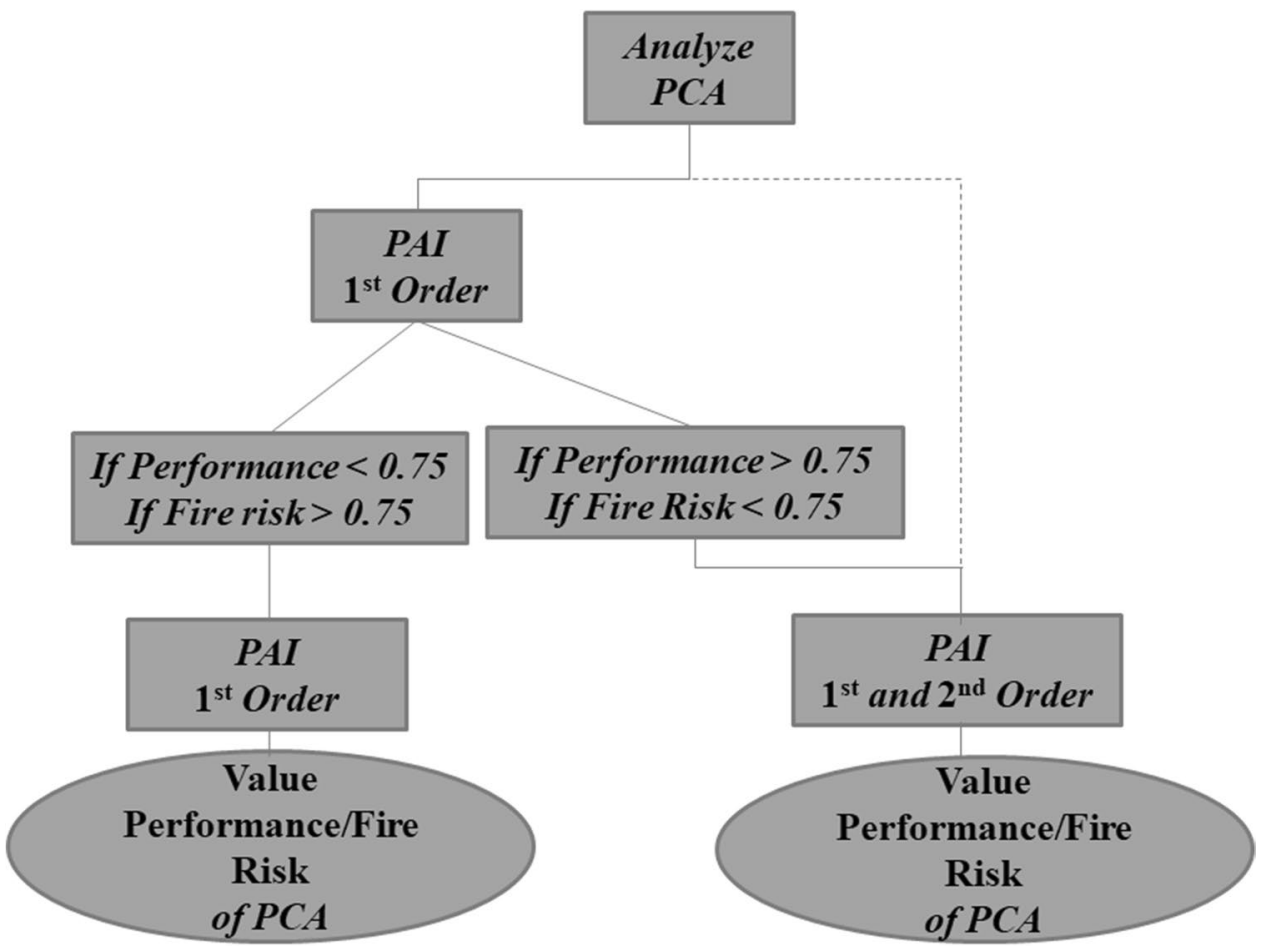


and in the other occurs a specific analysis in function of potential fire scenarios.

\section{Analysis in function of a standard reference performance}

This analysis is carried out by a methodology that compares the real or potential performance of the PAI with a standard performance of reference, named as Optimized Performance of the Function (OPF). The assessment is performed by a grid of four performance levels (PL) that correspond to the Potential of Loss of Function $\left(\mathrm{I}_{\mathrm{LF}}\right)$ indicator, taking into account Qualitative (QLC) and Quantitative (QTC) performance criteria. An example of the analysis criteria of a PAI can be seen in Fig. 5 .

Determination of fire safety performance indexes According to the National Fire Protection Association [8], fire safety depends on two main pillars: i) the potential of ignition (fire prevention) and ii) the potential of protection on control of the fire effects. Although this organization considers these two pillars as independent, it also recommends that these pillars should be analyzed together for reaching the fire safety objectives.
Critical component performance indexes The PEFIRA methodology analyzes and quantitatively determines the overall fire safety performance of a building $\left(\mathrm{PFS}_{\mathrm{GLOB}}\right)$ using Performance Indexes (PI) of the critical components for fire safety. The performance index of each PAI $\left(\mathrm{PI}_{\mathrm{PAI}}\right)$ is determined by the inverse of its failure potential by comparing to its Optimized Performance of the Function (OPF) (Fig. 6).

In addition to the $\mathrm{PI}_{\mathrm{PAI}}$, PEFIRA determines the Performance Index of each Performance Critical Area $\left(\mathrm{PI}_{\mathrm{PCA}}\right)$ by the average of the respective $\left(\mathrm{PI}_{\mathrm{PAI}}\right)$ (1). The methodology also determines the Performance Index of each Performance Action Domain ( $\left.\mathrm{PI}_{\mathrm{PAD}}\right)(2)$, as well as the performance of the Prevention Index (PIprev) (3) and the Protection Index (PIprot) (4) by the average of their PCA.

$P I_{P C A j} \frac{\sum_{i=1}^{n} P I_{P A I i}}{n}$

$P I_{P A D k}=\frac{\sum_{j=1}^{m} P I_{P C A j}}{m}$

\begin{tabular}{|c|c|c|c|c|c|}
\hline \multicolumn{6}{|c|}{ PERFORMANCE INDICATOR ANALYSIS CRITERIA SHEET } \\
\hline IND: & \multicolumn{4}{|c|}{ Prevention } & PAI 3 \\
\hline PAD: & \multicolumn{5}{|c|}{ Ignition potential } \\
\hline PCA: & \multicolumn{5}{|c|}{ Ignition source condition } \\
\hline PAI: & \multicolumn{2}{|c|}{ Control of hot or open flame work } & \multicolumn{3}{|c|}{ PO: $1^{\text {st }}$ Order (Life risk) } \\
\hline OPF: & \multicolumn{5}{|c|}{ Absence or adequate and effective control of all hot or open flame work. } \\
\hline QLC: & \multicolumn{5}{|c|}{$\begin{array}{l}\text { - Adequate and effective process for controlling hot or open flame work. } \\
\text { - Formalization of the process in written document. } \\
\text { - Existence of authorization of hazardous work in written document. } \\
\text { - Proper and effective implementation of hazardous work process. } \\
\text { - Knowledge of the process by all the usual occupants of the building. } \\
\text { - Evidence of compliance with all hazardous work procedures. }\end{array}$} \\
\hline LF & PL & \multicolumn{2}{|l|}{ General Criteria of Analysis } & \multicolumn{2}{|c|}{ QTC } \\
\hline Total & PLF4 & \multicolumn{2}{|c|}{$\begin{array}{l}\text { There is no formal process for controlling hazardous work or if there is, the process meets only } \\
\text { a small part of the qualitative performance criteria. }\end{array}$} & \multicolumn{2}{|l|}{$<40 \%$} \\
\hline Partial & PLF3 & \multicolumn{2}{|c|}{$\begin{array}{l}\text { There is a formal process for controlling hazardous work that meets only part of the qualitative } \\
\text { performance criteria. }\end{array}$} & \multicolumn{2}{|c|}{$\geq 40 \%$ and $<70 \%$} \\
\hline Localized & PLF2 & \multicolumn{2}{|l|}{$\begin{array}{l}\text { There is a formal process for controlling hazardous work that meets most qualitative } \\
\text { performance criteria. }\end{array}$} & \multicolumn{2}{|c|}{$\geq 70 \%$ and $<100 \%$} \\
\hline No loss & PLF1 & \multicolumn{2}{|c|}{$\begin{array}{l}\text { There is a formal process for controlling hazardous work that meets all qualitative performance } \\
\text { criteria. }\end{array}$} & \multicolumn{2}{|l|}{$100 \%$} \\
\hline
\end{tabular}

IND - General indicator; PAD - Performance Action Domain; PCA - Performance Critical Area; PAI - Performance Analysis Indicator; OPF - Optimized Performance of the Function; PO - Performance Analysis Priority Order, DL - Deficiency Level; LF - Loss of function; QLC - Qualitative performance criteria; QTC - Quantitative performance criteria.

Fig. 5 PAI analysis criteria sheet 


\begin{tabular}{|c|c|c|c|c|c|}
\hline \multicolumn{6}{|c|}{ PERFORMANCE INDICATOR ANALYSIS CRITERIA SHEET } \\
\hline IND: & \multicolumn{4}{|c|}{ Prevention } & PAI 3 \\
\hline PAD: & \multicolumn{5}{|c|}{ Ignition potential } \\
\hline PCA: & \multicolumn{5}{|c|}{ Ignition source condition } \\
\hline PAI: & \multicolumn{2}{|c|}{ Control of hot or open flame work } & \multicolumn{3}{|c|}{ PO: $1^{\text {st }}$ Order (Life risk) } \\
\hline OPF: & \multicolumn{5}{|c|}{ Absence or adequate and effective control of all hot or open flame work. } \\
\hline QLC: & \multicolumn{5}{|c|}{$\begin{array}{l}\text { - Adequate and effective process for controlling hot or open flame work. } \\
\text { - Formalization of the process in written document. } \\
\text { - Existence of authorization of hazardous work in written document. } \\
\text { - Proper and effective implementation of hazardous work process. } \\
\text { - Knowledge of the process by all the usual occupants of the building. } \\
\text { - Evidence of compliance with all hazardous work procedures. }\end{array}$} \\
\hline LF & PL & \multicolumn{2}{|l|}{ General Criteria of Analysis } & \multicolumn{2}{|c|}{ QTC } \\
\hline Total & PLF4 & \multicolumn{2}{|c|}{$\begin{array}{l}\text { There is no formal process for controlling hazardous work or if there is, the process meets only } \\
\text { a small part of the qualitative performance criteria. }\end{array}$} & \multicolumn{2}{|l|}{$<40 \%$} \\
\hline Partial & PLF3 & \multicolumn{2}{|c|}{$\begin{array}{l}\text { There is a formal process for controlling hazardous work that meets only part of the qualitative } \\
\text { performance criteria. }\end{array}$} & \multicolumn{2}{|c|}{$\geq 40 \%$ and $<70 \%$} \\
\hline Localized & PLF2 & \multicolumn{2}{|l|}{$\begin{array}{l}\text { There is a formal process for controlling hazardous work that meets most qualitative } \\
\text { performance criteria. }\end{array}$} & \multicolumn{2}{|c|}{$\geq 70 \%$ and $<100 \%$} \\
\hline No loss & PLF1 & \multicolumn{2}{|c|}{$\begin{array}{l}\text { There is a formal process for controlling hazardous work that meets all qualitative performance } \\
\text { criteria. }\end{array}$} & \multicolumn{2}{|l|}{$100 \%$} \\
\hline
\end{tabular}

IND - General indicator; PAD - Performance Action Domain; PCA - Performance Critical Area; PAI - Performance Analysis Indicator; OPF - Optimized Performance of the Function; PO - Performance Analysis Priority Order, DL - Deficiency Level; LF - Loss of function; QLC - Qualitative performance criteria; QTC - Quantitative performance criteria.

Fig. 6 Optimized function performance of the PAI for hot work and open flame work control

$$
\begin{aligned}
P I_{P R E V p} & =\frac{\sum_{k=1}^{l} P I_{P C A k}}{l} \\
P I_{\text {PROTl }} & =\frac{\sum_{k=1}^{p} P I_{P C A k}}{p}
\end{aligned}
$$

Being that:

$\mathrm{n}$-number of PAI that constitute the PCA; $\mathrm{m}$-number of PCA that constitute the PAD;

1 -number of PCA that constitute the $\mathrm{I}_{\mathrm{PREV}}$;

$\mathrm{p}$-number of PCA that constitute the $\mathrm{I}_{\mathrm{PROT}}$.

Global fire safety performance The global fire safety performance of the building $\left(\mathrm{P}_{\mathrm{FSGLOB}}\right)$ is determined by a performance matrix shown in Table 1 . In this way, PEFIRA methodology generates partial and total performance results of the fire safety system installed in the building, being an example of the first the $\mathrm{PI}_{\mathrm{PAD}}$ of each of the eight PAD (Fig. 7) and of the second the $\mathrm{PFS}_{\mathrm{GLOB}}$ (Fig. 8).

\section{Fire risk estimate and assessment process}

The fire risk analysis process is intended to understand its nature and determine its magnitude. For this, the present model facilitates the analysis of the fire risk factors present in the building, the level of potential fire exposure and the risk estimation of its materialization. This process uses Performance Analysis Indicators (PAI), for each the model determines its Fire Risk Index $\left(\operatorname{IR}_{\text {PAI }}\right)$, that is how much this indicator contributes to the global fire risk of the building $\left(\mathrm{RI}_{\mathrm{GLOB}}\right)$, using the algorithm presented in Fig. 9. This algorithm allows estimating the $\operatorname{IR}_{\mathrm{PAI}}$ taking into account the level of probability and severity resulting from the Loss of Function $\left(\mathrm{P}_{\mathrm{LF}}\right)$ of each PAI, being this potential of failure valued by a comparative method between the performance of the PAI and a previously defined Optimized Standard Performance (OPF), that is

\begin{tabular}{|c|c|c|c|c|c|}
\hline \multicolumn{6}{|c|}{$\begin{array}{l}\text { Global performance of fire safety system } \\
\text { (РFS,Lов) }\end{array}$} \\
\hline & & \multicolumn{4}{|c|}{ PIPRev } \\
\hline & & 1 & 2 & 3 & 4 \\
\hline \multirow{4}{*}{$\stackrel{5}{\stackrel{5}{2}}$} & 1 & Very efficient & Very efficient & Efficient & Deficient \\
\hline & 2 & Very efficient & Efficient & Efficient & Deficient \\
\hline & 3 & Efficient & Efficient & Deficient & Very deficient \\
\hline & 4 & Deficient & Deficient & Very deficient & Very deficient \\
\hline
\end{tabular}

Table 1 Global fire safety performance matrix 
Fig. 7 Performance indexes of each PAD

Fig. 8 Global fire safety performance index

Fig. 9 Algorithm for $\mathrm{FR}_{\mathrm{PAI}}$ assessment
Performance Indexes

PIPAD

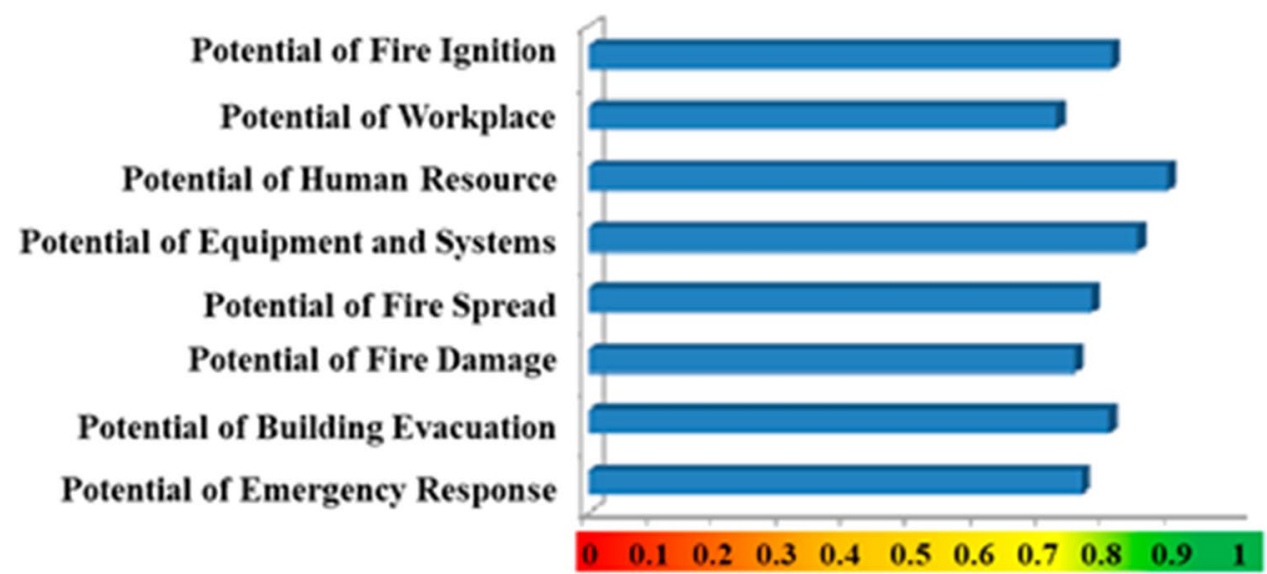

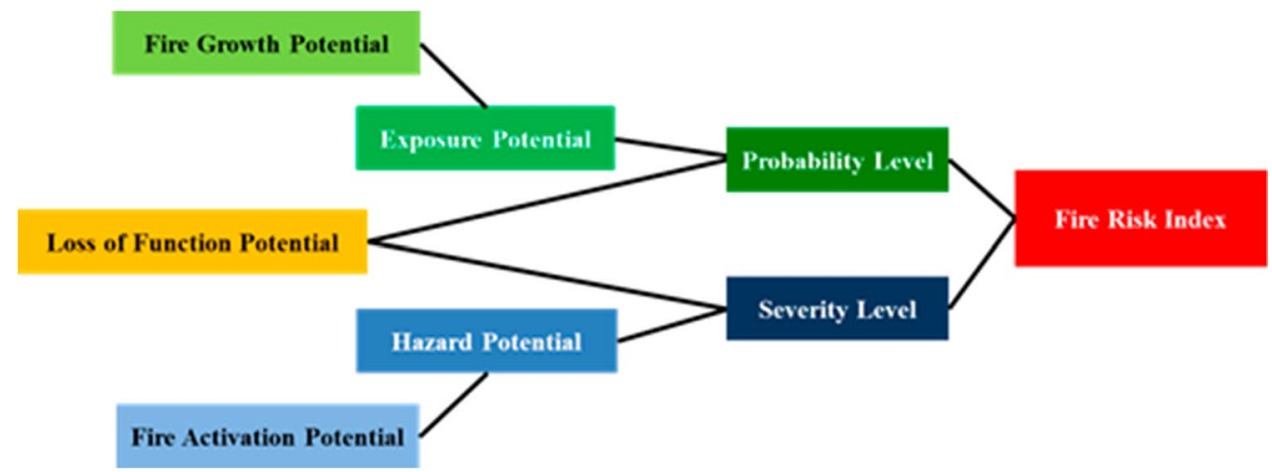

based on performance quantitative and qualitative criteria (Fig. 10). These quantitative criteria (QTC) and qualitative criteria (QLC) are red shadowed in Fig. 10. They allow analyzing the performance of the fire barrier at the level of each PAI and the consequent fire risk arising from its potential of failure.

\section{Determination of the probability level}

The probability level $\left(\mathrm{L}_{\mathrm{PROB}}\right)$ is determined by means of a weighted average that integrates the Potential of Loss of Function $\left(\mathrm{P}_{\mathrm{LF}}\right)$ of each PAI and the Potential of Fire Exposure $\left(\mathrm{P}_{\mathrm{EXP}}\right)$. The weighting values of these two variables 


\begin{tabular}{|c|c|c|c|c|c|}
\hline \multicolumn{6}{|c|}{ PERFORMANCE INDICATOR ANALYSIS CRITERIA SHEET } \\
\hline IND: & \multicolumn{4}{|c|}{ Prevention } & PAI 3 \\
\hline PAD: & \multicolumn{5}{|c|}{ Ignition potential } \\
\hline PCA: & \multicolumn{5}{|c|}{ Ignition source condition } \\
\hline PAI: & \multicolumn{2}{|c|}{ Control of hot or open flame work } & \multicolumn{3}{|c|}{ PO: $1^{\text {st }}$ Order (Life risk) } \\
\hline OPF: & \multicolumn{5}{|c|}{ Absence or adequate and effective control of all hot or open flame work. } \\
\hline QLC: & \multicolumn{5}{|c|}{$\begin{array}{l}\text { - Adequate and effective process for controlling hot or open flame work. } \\
\text { - Formalization of the process in written document. } \\
\text { - Existence of authorization of hazardous work in written document. } \\
\text { - Proper and effective implementation of hazardous work process. } \\
\text { - Knowledge of the process by all the usual occupants of the building. } \\
\text { - Evidence of compliance with all hazardous work procedures. }\end{array}$} \\
\hline LF & PL & \multicolumn{2}{|l|}{ General Criteria of Analysis } & \multicolumn{2}{|c|}{ QTC } \\
\hline Total & PLF4 & \multicolumn{2}{|c|}{$\begin{array}{l}\text { There is no formal process for controlling hazardous work or if there is, the process meets only } \\
\text { a small part of the qualitative performance criteria. }\end{array}$} & \multicolumn{2}{|l|}{$<40 \%$} \\
\hline Partial & PLF3 & \multicolumn{2}{|c|}{$\begin{array}{l}\text { There is a formal process for controlling hazardous work that meets only part of the qualitative } \\
\text { performance criteria. }\end{array}$} & \multicolumn{2}{|c|}{$\geq 40 \%$ and $<70 \%$} \\
\hline Localized & PLF2 & \multicolumn{2}{|l|}{$\begin{array}{l}\text { There is a formal process for controlling hazardous work that meets most qualitative } \\
\text { performance criteria. }\end{array}$} & \multicolumn{2}{|c|}{$\geq 70 \%$ and $<100 \%$} \\
\hline No loss & PLF1 & \multicolumn{2}{|c|}{$\begin{array}{l}\text { There is a formal process for controlling hazardous work that meets all qualitative performance } \\
\text { criteria. }\end{array}$} & \multicolumn{2}{|l|}{$100 \%$} \\
\hline
\end{tabular}

IND - General indicator; PAD - Performance Action Domain; PCA - Performance Critical Area; PAI - Performance Analysis Indicator; OPF - Optimized Performance of the Function; PO - Performance Analysis Priority Order, DL - Deficiency Level; LF - Loss of function; QLC - Qualitative performance criteria; QTC - Quantitative performance criteria.

Fig. 10 Quantitative (QTC) and qualitative (QLC) criteria for performance analysis

are fixed, as defined in Eq. (3) of Fig. 11. The $\mathrm{P}_{\text {EXP }}$ corresponds to the highest level of the Intrinsic Fire Risk Factor $\left(\mathrm{L}_{\text {IFRF }}\right.$ ) relative to the theoretical number of building occupants (Table 2), aggravated by a Correction Factor (CF) as a function of Fire Growth Potential $\left(\mathrm{P}_{\mathrm{G}}\right)($ Table 4$)$, defined in Eq. (1) of Fig. 11.

The weighting values used in Eq. (3) that determines the level of probability are constant, having been selected empirically and they have shown great reliability and regularity to the method, after studies carried out based on the theory of extremes.

The pre-established values for the $\mathrm{L}_{\mathrm{IFRF}}$ and the CF proposed in Table 3 are based in the analysis of the common values indicated in the international standards and regulations and articles of the area [9-13].

The Potential Loss of Function of each PAI is determined by the pre-established general performance criteria for the four Performance Levels (PL) (Fig. 11).

\section{Determination of the severity level}

The severity level $\left(\mathrm{L}_{\mathrm{SEVE}}\right)$ is determined by means of a weighted average that integrates the Potential Loss of
Function $\left(\mathrm{P}_{\mathrm{LF}}\right)$ of each PAI and the Hazard Potential $\left(\mathrm{P}_{\mathrm{HAZ}}\right)$ relative to it (Fig. 11). The weighting values of these two variables are determined by Eq. (4) (Fig. 11). The $\mathrm{P}_{\mathrm{HAZ}}$ corresponds to the highest level of the Intrinsic Fire Risk Factors $\left(\mathrm{L}_{\mathrm{IFRF}}\right)$ determined for the building from those listed in Table 4, aggravated by a Correction Factor (CF) as a function of the Fire Activation Potential $\left(\mathrm{P}_{\mathrm{A}}\right)$ referred in Table 5, and calculated by Eq. (2) (Fig. 11). The pre-established values for the $\mathrm{L}_{\text {IFRF }}$ proposed in Table 5 and the CF in Table 6 are based on the analysis of the common values proposed in the international standards and regulations and papers of the areas [9-13].

\section{determination of fire risk indexes}

The PEFIRA methodology analyzes and quantitatively determines how much each of the critical components for fire safety contributes to the building's Global Fire Risk $\left(\mathrm{FR}_{\mathrm{GLOB}}\right)$. This contribution can be verified by the Fire Risk Index (RI) estimated for each component. The valuing of the Fire Risk Index $\left(\mathrm{RI}_{\mathrm{PAI}}\right)$ of each PAI is defined based on Table 6 that integrates the Probability Level and the Severity Level. 


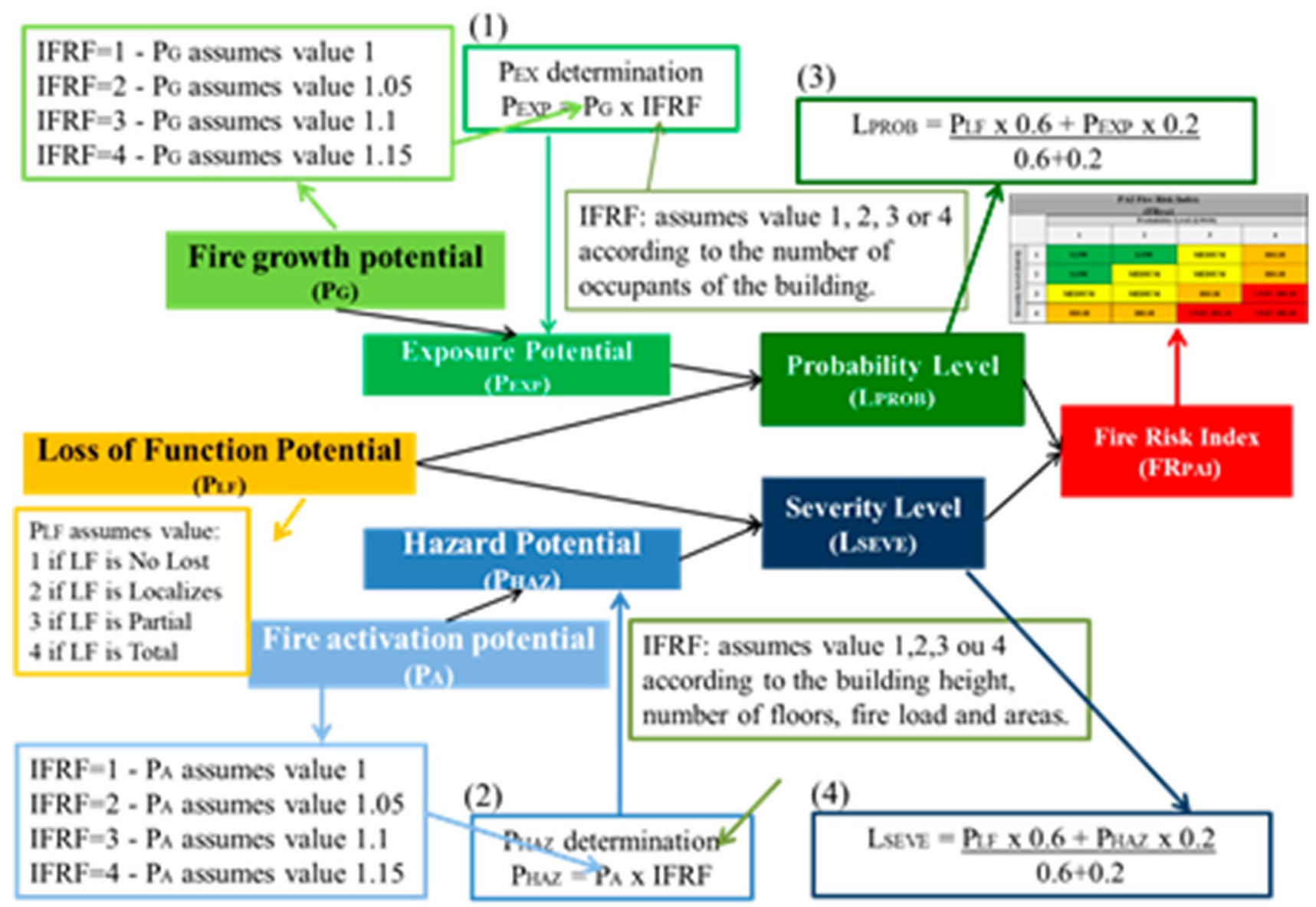

Fig. 11 Algorithm for determining the Fire Risk Index of each PAI

In addition to $\mathrm{RI}_{\mathrm{PAI}}$, PEFIRA determines the Fire Risk Index of each Performance Critical Area $\left(\mathrm{RI}_{\mathrm{PCA}}\right)$ by a simple average of the respective ( $\left.\mathrm{RI}_{\mathrm{PAI}}\right)$ (5). It also determines the Risk Index of the Performance Action Domain $\left(\mathrm{RI}_{\mathrm{PAD}}\right)$ (6), as well as the prevention index ( $\mathrm{RI}_{\mathrm{PREV}}$ ) (7) and the protection index $\left(\mathrm{RI}_{\mathrm{PROT}}\right)(8)$ by a weighted average of the respective PAI.

$$
\begin{aligned}
& R I_{P C A j} \frac{\sum_{i=1}^{n} R I_{P A I i}}{n} \\
& R I_{P A D k}=\frac{\sum_{j=1}^{m} w_{R I_{P C A j}} \times R I_{P C A j}}{\sum_{j=1}^{m} w_{R I_{P C A j}}} \\
& R I_{P R E V p}=\frac{\sum_{k=1}^{l} w_{R I_{P C A k}} \times R I_{P C A k}}{\sum_{k=1}^{l} w_{R I_{P C A k}}} \\
& R I_{P R O T l}=\frac{\sum_{k=1}^{p} w_{R I_{P C A k}} \times R I_{P C A k}}{\sum_{k=1}^{p} w_{R I_{P C A k}}}
\end{aligned}
$$

with:

$\mathrm{n}$-number of PAI that constitute the PCA;

$\mathrm{m}$-number of PAI that constitute the PAD;

l-number of PAI that constitute the Prevention Index $\left(\mathrm{I}_{\text {PREV }}\right)$;

$\mathrm{p}$-number of PAI that constitute the Protection Index $\left(\mathrm{I}_{\mathrm{PROT}}\right)$;

$\mathrm{w}$-weighting factors.

\section{Fire risk weighting and correction factors}

In a performance-based fire risk assessment model, a number of parameters that contribute to the fire development must be identified and adequately addressed. According to [14], the parameters that control the fire development can be either deterministic or of random nature. Assuming that the reliability of a multi-fire risk scenario assessment model will depend on an adequate integration of all critical fire safety components, the mathematical model used by PEFIRA incorporates a large number of such components, Corrected Factors (CF) and Weighting Factors (WF). The CF assume the values mentioned in Tables 4 and 6 according to their respective Intrinsic Fire Risk Factors (IFRF). They are used 
Table 2 Intrinsic fire risk factors for $\mathrm{P}_{\mathrm{EXP}}$ determination

\begin{tabular}{lll}
\hline Building occupation type & Number of occupants & L FIRI \\
\hline $\begin{array}{l}\text { Schools, shops and transport stations, libraries, archives, muse- } \\
\text { ums and art galleries }\end{array}$ & $\leq 100$ & 1 \\
& $>100 \leq 500$ & 2 \\
& $>500 \leq 1500$ & 3 \\
Administrative, shows, meetings and sports and leisure & $>1500$ & 4 \\
& $\leq 100$ & 1 \\
Outdoor open areas & $>100 \leq 1000$ & 2 \\
& $>1000 \leq 5000$ & 3 \\
Sleeping & $>5000$ & 4 \\
& $\leq 1000$ & 1 \\
& $>1000 \leq 1500$ & 2 \\
alarm perception & $>1500 \leq 4000$ & 3 \\
& $>4000$ & 4 \\
& $\leq 50$ & 1 \\
& $>50 \leq 200$ & 2
\end{tabular}

as factors that aggravate the risk with respect to the Exposure Potential $\left(\mathrm{P}_{\mathrm{EXP}}\right)$ and Hazard Potential $\left(\mathrm{P}_{\mathrm{HAZ}}\right)$ (see Eq. 1 and 2 of Fig. 11) in the process of determining the $\mathrm{RI}_{\mathrm{PAI}}$. The WF assume the values mentioned in Tables 8 and 9 and are used to weight the average of the Performance Critical Areas (PCA) in the process of determining the $\mathrm{FR}_{\mathrm{GLOB}}$, given the increased importance assumed by the random factors called as Extrinsic Fire Risk Factors (EFRF) in face of the constraints imposed by the Intrinsic Fire Risk Factors (IFRF).

\section{Intrinsic fire risk factors}

The Intrinsic Fire Risk Factors (IFRF) are critical fire safety factors inherent to each type of building or occupancy and are therefore considered to be coexistent with the respective typologies, with no possibility of elimination or control. These deterministic factors are identified and valued as a function of the Reference Fire Risk Factor

Table 3 Correction factors (CF) as a function of fire growth potential $\left(\mathrm{P}_{\mathrm{G}}\right)$

\begin{tabular}{lll}
\hline $\begin{array}{l}\text { Fire Growth } \\
\text { Potential }\left(\mathrm{P}_{\mathrm{G}}\right)\end{array}$ & $\mathrm{L}_{\mathrm{IFRF}}$ & $\mathrm{CF}$ \\
\hline Slow & 1 & 1 \\
Medium & 2 & 1.05 \\
Fast & 3 & 1.1 \\
Ultra fast & 4 & 1.15 \\
\hline
\end{tabular}

(RFRF) determined by PEFIRA after the characterization of the building under analysis. The following specific IFRF are considered for determining the specific weighting (Ws) values: (i) existence of children under the age of 3, (ii) exih of the weightinggrades forstence of occupants with disabilities that difficult the mobility and alarm perception or bedridden, (iii) existence of occupants not familiar with the building (public), (iv) existence of occupants familiar with the building but sleeping on it, (v) existence of occupants not familiar with the building (public) but sleeping on it, (vi) existence of floors below the reference floor, (vii) existence of floors above reference floor, (viii) planimetry and complexity of the floor, (ix) existence of high fire load density and (x) existence of high risk of fire activation.

\section{Extrinsic fire risk factors}

The Extrinsic Fire Risk Factors (EFRF) are critical fire safety factors that may be randomly present, regardless the building type or occupancy, depending those on the potential of loss of function of one or more of the critical components contributing to fire safety. These factors can be eliminated or their risks controlled. An example of an EFRF is the malfunction of an electrical installation that could potentially origin the fire. 
Table 4 Intrinsic fire risk factors for $\mathrm{P}_{\mathrm{HAZ}}$ determination

\begin{tabular}{|c|c|c|}
\hline Buildings & Height (m) & $\mathrm{L}_{\mathrm{IFRF}}$ \\
\hline & $\leq 9$ & 1 \\
\hline & $>9 \leq 28$ & 2 \\
\hline & $>28 \leq 50$ & 3 \\
\hline & $>50$ & 4 \\
\hline \multirow[t]{5}{*}{ Underground car parks } & Number of Floors & $\mathrm{L}_{\text {IFRF }}$ \\
\hline & $\leq 1$ & 1 \\
\hline & $>1 \leq 3$ & 2 \\
\hline & $>3 \leq 5$ & 3 \\
\hline & $>5$ & 4 \\
\hline \multirow[t]{5}{*}{ Underground industry and storage } & Number of Floors & $\mathrm{L}_{\text {IFRF }}$ \\
\hline & 0 & 1 \\
\hline & 1 & 2 \\
\hline & $>1 \leq 2$ & 3 \\
\hline & $>2$ & 4 \\
\hline Fire load density & $\left(\mathrm{MJ} / \mathrm{m}^{3}\right)$ & $\mathrm{L}_{\text {IFRF }}$ \\
\hline \multirow[t]{4}{*}{ Storage inside the building } & $\leq 5000$ & 1 \\
\hline & $>5000 \leq 50,000$ & 2 \\
\hline & $>50,000 \leq 150,000$ & 3 \\
\hline & $>150,000$ & 4 \\
\hline \multirow{4}{*}{$\begin{array}{l}\text { Storage outside the building and } \\
\text { archives }\end{array}$} & $\leq 10,000$ & 1 \\
\hline & $>10,000 \leq 100,000$ & 2 \\
\hline & $>100,000 \leq 300,000$ & 3 \\
\hline & $>300,000$ & 4 \\
\hline \multirow[t]{5}{*}{ Industry inside the building } & $\left(\mathrm{MJ} / \mathrm{m}^{2}\right)$ & $\mathrm{L}_{\text {IFRF }}$ \\
\hline & $\leq 500$ & 1 \\
\hline & $>500 \leq 5000$ & 2 \\
\hline & $>5000 \leq 15,000$ & 3 \\
\hline & $>15,000$ & 4 \\
\hline \multirow{4}{*}{$\begin{array}{l}\text { Industry outside the building and } \\
\text { libraries }\end{array}$} & $\leq 1000$ & 1 \\
\hline & $>1000 \leq 10,000$ & 2 \\
\hline & $>10,000 \leq 30,000$ & 3 \\
\hline & $>30,000$ & 4 \\
\hline \multirow[t]{5}{*}{ Planimetry } & $\left(\mathrm{m}^{2}\right)$ & $\mathrm{L}_{\text {IFRF }}$ \\
\hline & $\leq 400$ & 1 \\
\hline & $>400 \leq 1600$ & 2 \\
\hline & $>1600 \leq 3600$ & 3 \\
\hline & $>3600$ & 4 \\
\hline \multirow[t]{5}{*}{ Gross area of car parks } & $\left(\mathrm{m}^{2}\right)$ & $\mathrm{L}_{\text {IFRF }}$ \\
\hline & $\leq 3200$ & 1 \\
\hline & $>3200 \leq 9600$ & 2 \\
\hline & $>9600 \leq 32,000$ & 3 \\
\hline & $>32,000$ & 4 \\
\hline
\end{tabular}

\section{Critical performance areas of the weighting process}

The weighting factors are used to weight the integration of the Performance Critical Areas (PCA) in the mathematical
Table 5 Correction factors (CF) as a function of the fire activation potential $\left(\mathrm{P}_{\mathrm{A}}\right)$

\begin{tabular}{lll}
\hline $\begin{array}{l}\text { Fire activation } \\
\text { potential }\left(\mathrm{P}_{\mathrm{A}}\right)\end{array}$ & IFRF & $\mathrm{CF}$ \\
\hline Low & 1 & 1 \\
Medium & 2 & 1.05 \\
High & 3 & 1.1 \\
Very High & 4 & 1.15 \\
\hline
\end{tabular}

model that determines the building's Global Fire Risk $\left(\mathrm{FR}_{\mathrm{GLOB}}\right)$ in function of the Intrinsic Fire Risk Factors resulting from their nature and type of occupation. The weighting process results from the relative importance of each PCA in achieving the maintenance of the fire safety conditions. In this sense, PEFIRA methodology carried out a general and also several specific weights (as many as the intrinsic fire risk factors imposed by the nature of the building and its occupancy).

In the determination of the weighting factors (WF), a Delphi methodology was used recurring to a panel of fire experts to whom was sent a survey with six questions. The first question asked to rank, by its relevance to fire safety in buildings, each of the 28 PCA within the following grades: 1- Irrelevant; 2-Not important; 3-Important; 4-Very important; 5- Extremely important. The second question requested giving values between 0.1 to 1 for each of the weighting grades for buildings of minimum RFRF that are not destined to receive children under the age of six, persons with limited mobility or limited capabilities to alarm perception and reaction, bedridden people and activities of high risk of fire outbreak. In the third question it was asked whether the weighting values assigned in the second question should be increased and if so to choose a value between +0.01 and +0.15 , this for buildings of minimum RFRF that are dedicated to receive children under the age of six, persons with limited mobility or limited capabilities to alarm perception and reaction. The fourth question asked if the weighting values assigned in the second question should be increased and if so to choose a value between +0.01 and +0.15 for buildings of minimum RFRF destined to receive bedridden people. The fifth question asked if the weighting values given in the second question should be increased and if so to choose one in the interval between +0.01 and +0.15 for buildings of minimum RFRF destined to receive activities of high risk of fire outbreak. Finally, in the sixth question it was asked if the weighting values assigned in the second question should be increased and if so to give values between +0.01 and +0.15 for buildings of RFRF equals to 2, 3 and 4 that are not destined to receive children under the age of six, persons with limited mobility or capability to perceive and react to the alarm and activities of high risk of fire outbreak. In the third, fourth and fifth questions the experts could also propose values outside the proposed interval but 
justifying their decision. The consensus reached with this technique allowed the elaboration of Table 8 with a grid for general and specific weighting values.

\section{Overall weighting}

The overall weighting affects all PCA being obtained by adding the value of the Base Weight $\left(\mathrm{W}_{\mathrm{b}}\right)$ with the value of the Complementary Weight $\left(\mathrm{W}_{\mathrm{c}}\right)$. The first is pre-established according to the relative importance of each PCA for the fire control and its development, as well as for the mitigation of its effects, being tabulated by the minimum Reference Fire Risk Factor (RFRF 1) condition. The second is pre-established in function of the increasing importance of the PCAs in the process of compensating of the natural aggravation of the fire risk due to the increasing of the remaining reference fire risk factors (RFRF 2 to RFRF 4) (Table 7).

\section{Specific weighting}

The Specific Weighting (Ws) is performed at the level of each PCA and results of its relative importance for the global fire risk of the building imposed by the special hazards of the specific Intrinsic Fire Risk Factors (IFRF) that result from the specificity of certain characteristics of the buildings and their occupancies.

The Final Weight (Wf) value assumed by each PCA is obtained by adding the overall weights of specific weights $(\mathrm{Wf}=\mathrm{Wb}+\mathrm{Wc}+\mathrm{Ws})$. Thus, in the process of determining $\mathrm{FR}_{\mathrm{GLOB}}$, each PCA has higher weighting as higher the
Table 6 Fire risk matrix for determining the PAI's contribution to the overall fire risk

Table 7 PCA overall weighting values for the $\mathrm{FR}_{\mathrm{GLOB}}$ assessment

Table 8 PCA specific weighting factors for $\mathrm{FR}_{\mathrm{GLOB}}$ assessment.

\begin{tabular}{|c|c|c|c|c|c|}
\hline \multicolumn{6}{|c|}{$\begin{array}{c}\text { PAI Fire Risk Index } \\
\text { (RIPAI) }\end{array}$} \\
\hline & & \multicolumn{4}{|c|}{ Probability Level (LPROB) } \\
\hline & & 1 & 2 & 3 & 4 \\
\hline \multirow{4}{*}{ 离 } & 1 & Very low & Very low & Low & High \\
\hline & 2 & Very low & Low & Low & High \\
\hline & 3 & Low & Low & High & Very High \\
\hline & 4 & High & High & Very High & Very High \\
\hline
\end{tabular}

\begin{tabular}{|c|c|c|c|c|c|c|}
\hline \multirow{3}{*}{ RL } & \multirow{3}{*}{ Classification } & \multirow{3}{*}{ Theoretical bases } & \multicolumn{4}{|c|}{ General Weighting } \\
\hline & & & \multirow{2}{*}{$\frac{W_{b}}{\text { RFRF }}$} & \multicolumn{3}{|c|}{$\mathbf{W}_{\mathrm{c}}$} \\
\hline & & & & $\begin{array}{c}\text { RFRF } \\
2\end{array}$ & $\begin{array}{c}\text { RFRF } \\
\mathbf{3}\end{array}$ & $\begin{array}{c}\text { RFRF } \\
4\end{array}$ \\
\hline ++++++ & $\begin{array}{l}\text { Highly } \\
\text { Critical }\end{array}$ & $\begin{array}{l}\text { The absence of failure in PCA is highly relevant to fire } \\
\text { ignition control, its development or mitigation of its } \\
\text { effects. }\end{array}$ & 1 & 0.05 & 0.07 & 0.09 \\
\hline ++++ & $\begin{array}{l}\text { Very } \\
\text { Critical }\end{array}$ & $\begin{array}{l}\text { The absence of failure in PCA is very relevant to fire } \\
\text { ignition control, its development or mitigation of its } \\
\text { effects. }\end{array}$ & 0.8 & 0.04 & 0.06 & 0.08 \\
\hline+++ & Critical & $\begin{array}{l}\text { The absence of failure in PCA is relevant to fire ignition } \\
\text { control, its development or mitigation of its effects. }\end{array}$ & 0.6 & 0.03 & 0.05 & 0.07 \\
\hline++ & $\begin{array}{l}\text { Little } \\
\text { Critical }\end{array}$ & $\begin{array}{l}\text { The absence of failure in PCA is of little relevant to fire } \\
\text { ignition control, its development or mitigation of its } \\
\text { effects. }\end{array}$ & 0.4 & 0.02 & 0.04 & 0.06 \\
\hline+ & Uncritical & $\begin{array}{l}\text { The absence of failure in PCA is irrelevant to fire ignition } \\
\text { control, its development or mitigation of its effects. }\end{array}$ & 0.2 & 0.01 & 0.03 & 0.05 \\
\hline
\end{tabular}

\begin{tabular}{|c|c|l|c|}
\hline FL & Definition & \multicolumn{1}{|c|}{ Theoretical bases } & $\mathbf{W}_{\mathbf{s}}$ \\
\hline+++++ & $\begin{array}{c}\text { Highly } \\
\text { Critical }\end{array}$ & $\begin{array}{l}\text { The absence of failure in PCA is highly relevant to compensate the } \\
\text { constraints imposed by the Intrinsic Fire Risk Factors. }\end{array}$ & 0.15 \\
\hline $\mathbf{+ + + +}$ & $\begin{array}{c}\text { Very } \\
\text { Critical }\end{array}$ & $\begin{array}{l}\text { The absence of failure in PCA is very relevant to compensate the } \\
\text { constraints imposed by the Intrinsic Fire Risk factors. }\end{array}$ & 0.1 \\
\hline $\mathbf{+ + +}$ & Critical & $\begin{array}{l}\text { The absence of failure in PCA is relevant to compensate the } \\
\text { constraints imposed by the Intrinsic Fire Risk factors. }\end{array}$ & 0.05 \\
\hline++ & $\begin{array}{c}\text { Little } \\
\text { Critical }\end{array}$ & $\begin{array}{l}\text { The absence of failure in PCA is little relevant to compensate the } \\
\text { constraints imposed by the Intrinsic Fire Risk factors. }\end{array}$ & 0.03 \\
\hline
\end{tabular}


potential to compensate the constraints imposed by the respective IFRF and RFRF is. The Specific Weighting values are presented in Table 8.

\section{Global fire risk calculation}

PEFIRA methodology determines the Global Fire Risk $\left(\mathrm{FR}_{\mathrm{GLOB}}\right)$ that indicates the actual fire risk of the building. The $\mathrm{FR}_{\mathrm{GLOB}}$ is determined by a weighted average of the fire risk indexes of all PCA analyzed (9).

$F R_{G L O B} P=\frac{\sum_{k=1}^{l} w_{R I_{P C A k}} \times R I_{P C A k}}{\sum_{k=1}^{l} w_{R I_{P C A k}}}$

With:

1 - corresponding to all analyzed PCA;

$\mathrm{w}$-weighting factors.

\section{Analysis of fire safety performance with fire scenarios}

The analysis of fire safety performance with fire scenarios is carried out starting on the potential of failure of the PAI based on the previously selected fire scenarios. The fire scenarios are previously selected and represented by a technical description of the social expectation regarding fire safety. They should describe the critical factors for fire outbreak,

Table 9 Design fire scenarios used to analyze and validate fire protection

\section{Potential}

design fire

scenarios

DFS1 Hidden ignition inside walls or structures underlying places with significant human occupation ( $>20$ people)

DFS2 Ultra-fast growing fire affecting the main escape route with the doors open at the time of ignition

DFS3 Ignition in a normally unoccupied location that can spread to an adjacent location with significant number of people ( $>20$ people) endangering them

DFS4 Small fire that slowly develops from an inaccessible location to the fire protection means, close to a place of significant human occupation ( $>100$ people)

DFS5 Severe fire resulting from the largest fire load expected for the building activity, with the maximum number of occupants expected being present

DFS6 Fire that outbreaks in ordinary fuels in a location or area where each active or passive fire protection system became inoperative

DFS7 Outdoor fire that exposes the building and may block its evacuation or develop conditions that do not guarantee the sustainability of life such as the source of ignition, nature and configuration of fuels, ventilation, characteristics and location of occupants and structural conditions of the building [15]. Fire Design can be defined as a set of conditions regarding to the origin, spread and products released by the fire taking into account their effects on the people [16].

The National Fire Protection Association [9] further defines the concept of "Design Fire Scenarios" as the scenarios that can be selected for performing the evaluation of fire safety engineering solutions at a design stage, establishing for that eight scenarios type. The Design Fire Scenarios (DFS) should be based on the expected reality and developed in conformity to the type of building occupancy and in the worst conditions that should be reasonably foreseeable [17].

The fire scenarios are selected according to the risk of their materialization, taking into account the expected frequency that each scenario may occur and the reasonable foreseeable consequences of their materialization. The task of identifying and selecting the fire scenarios is part of the design phase and these scenarios should be sufficiently demanding to test the projects and their proposed alternatives to ensure that these proposals meet the fire safety requirements [18]. The process of screening of fire scenarios is done using the best available engineering judgements and a variety of deterministic and probabilistic tools, such as the event trees or the qualitative analysis methods $[19,20]$. In this analysis, the probability of materialization of fire scenarios is determined through a failure tree, depending on the failure potential of selected components of the Fire Prevention Index $\left(\mathrm{I}_{\mathrm{PREV}}\right)$. Figure 12 presents, as an example, the fault tree for risk analysis and materialization of DFS1.

According to the International Organization for Standardization (ISO) [21], to ensure the credibility of a fire safety analysis process, it is important to use a qualitative or semiquantitative approach. The Fire Risk Assessment and Cost Assessment Model (FiRECAM) developed by the National Research Council of Canada (NRC) uses six design fire scenarios from the fire outbreak with the consequent spread and smoke release for assessing the risks to life and costs of fire protection in office buildings [22].

PEFIRA methodology uses seven design fire scenarios described in Table 9 for evaluating and validating both the performance of fire protection conditions to be installed in buildings at a design stage and the fire safety means installed in the building (Figs. 12 and 13). The risk of materialization of fire scenarios is determined in function of the potential of failure of the selected components for the respective $I_{\text {PREV }}$ and $I_{\text {PROT }}$.

The use of design fire scenarios allows to assess and validate the fire safety engineering solutions that should be implemented or have already been implemented by a process based on the performance analysis of components considered as critical to Fire Safety (FS) in face of each of 

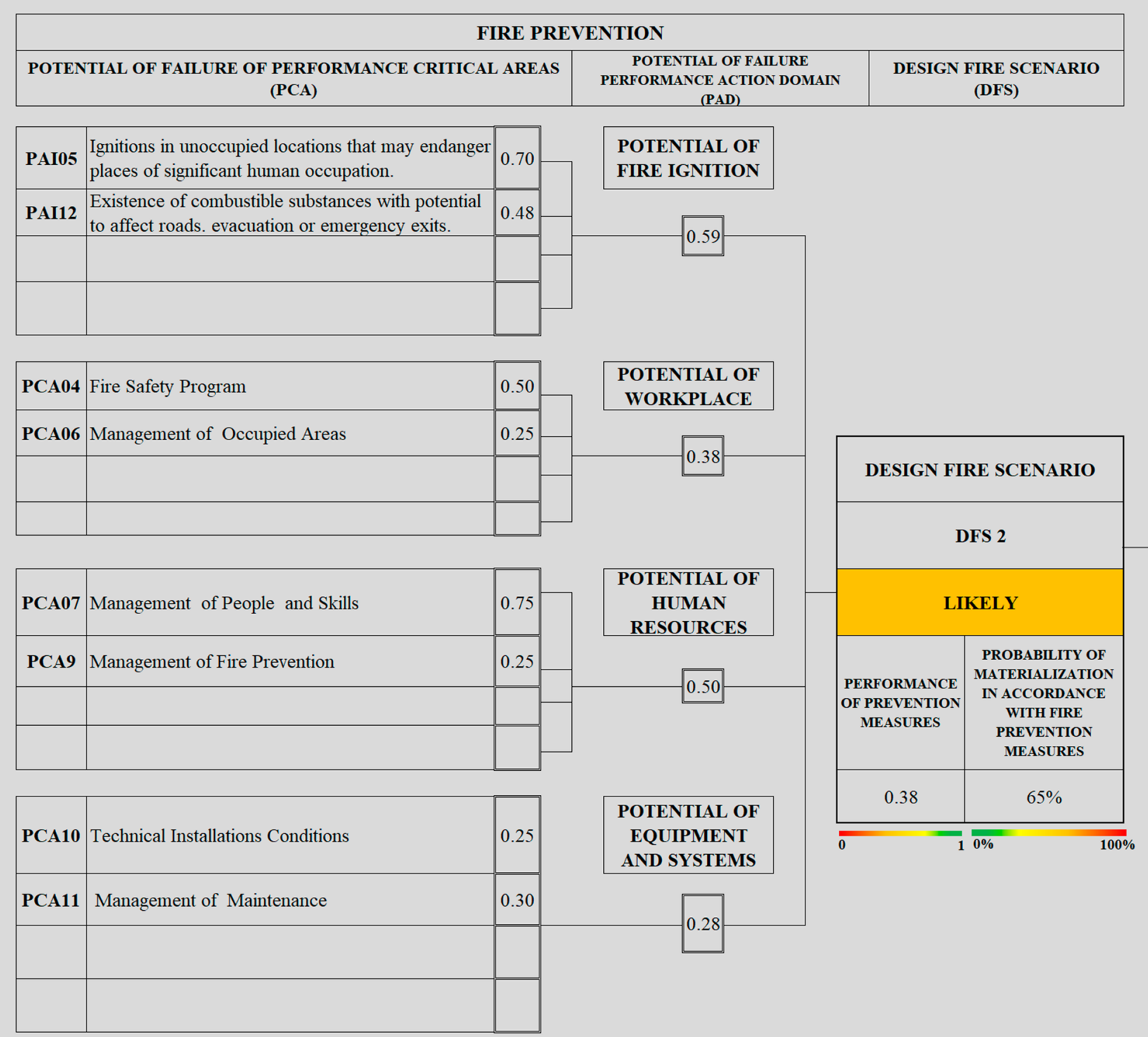

Fig. 12 Use of design fire scenarios to assess and validate $\mathrm{I}_{\mathrm{PREV}}$

those scenarios. PEFIRA methodology, when performing the performance-based assessment, determines the likelihood of each of the seven design fire scenarios to occur.

The consequences (severity) of the materialization of design fire scenarios are determined through an event tree, depending on the potential of failure of the selected components of the Fire Protection Index ( $\mathrm{I}_{\mathrm{PROT}}$ ). In Fig. 13, it is presented the event tree to analyze the consequences of the materialization of DFS1.

On the other hand, assuming that the DFS specifies the fire conditions that a given fire safety engineering proposal or technical solution is expected to meet its targets, it is assumed that this principle can be applied for assessing the purpose of the performance of emergency response potential. In this sense it was developed and integrated in PEFIRA a third concept of fire scenarios, called Emergency Response Fire Scenarios (ERFS). These scenarios are considered as a set of reasonable valid set of conditions that specify the critical factors of the fire, in face of which it is expected to be installed or has already been installed in the building a certain fire response condition in order to reach the necessary targets.

Based on the potential of failure of the analyzed PAI, PEFIRA methodology selects the design fire scenarios with the highest risk of materialization and in function of them, generates emergency response fire scenarios that 

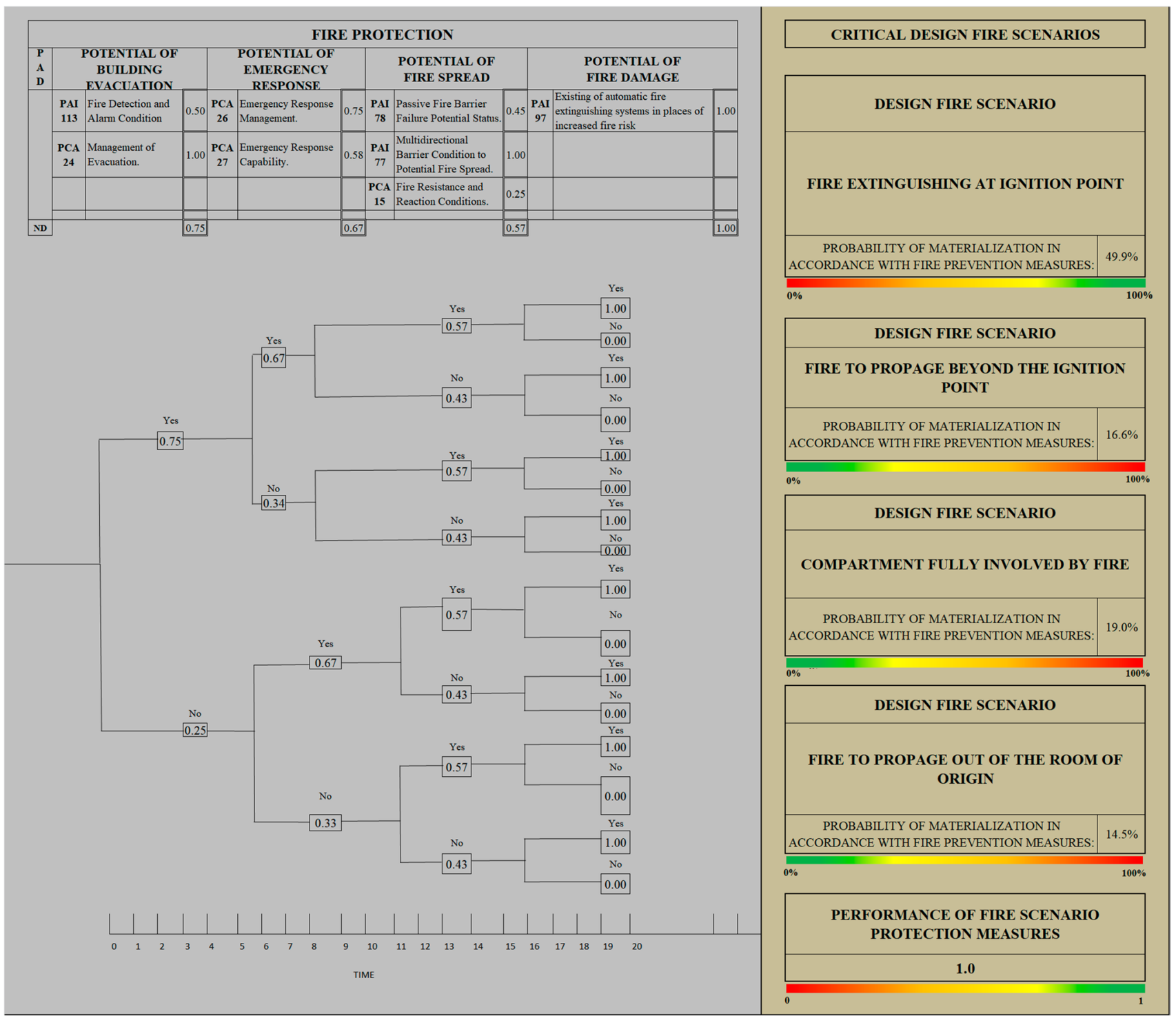

Fig. 13 Use of design fire scenarios to assess $\mathrm{I}_{\mathrm{PROT}}$ conditions

allow to validate the fire protection conditions installed or to be installed in the building and namely the means of fire response.

From the ERFS with highest risk of materialization, PEFIRA generates the Critical Emergency Response Fire Scenario (CERFS) which allows the assessment and validation of the fire protection conditions installed in the building, namely the fire response conditions in the building. Likewise, it generates the extreme Emergency Response Fire Scenario (ERFS) that allows validating the performance of the emergency public services (Fig. 14). These two types of ERFS, in addition to allow the assessment and validation of the emergency response conditions, they can be used for emergency planning purposes.
The process of determining the risk of materialization of the DFS is achieved by a fire-adapted "Bow-Tie" diagram, depending on the failure potential of the $\mathrm{I}_{\mathrm{PREV}}$ and $\mathrm{I}_{\mathrm{PROT}}$ components (Fig. 15).

This type of analysis relates in function of the time the conditions that affect the inside fire dynamics and the products released by it, with the performance of all parts of the fire protection system installed in the building. For this extent, on the basis of a representative profile of the fire compartment (fire curve) and using the above-mentioned diagnostic fire scenarios, the main events related to the fire growth, the functioning of the fire protection system and the behavior of the building's occupants, are analyzed on a basis of the fire time ribbon. This analysis allows to address critical aspects for the safety of occupants of a building in fire, 

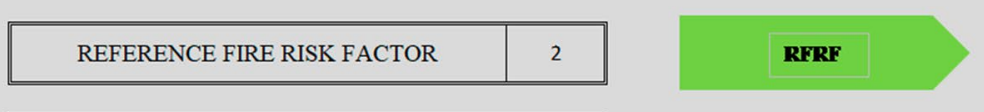

\begin{tabular}{|c||}
\hline EMERGENCY RESPONSE FIRE SCENARIO \\
(ERFS)
\end{tabular}

\begin{tabular}{|c|}
\hline EMERGENCY RESPONSE FIRE SCENARIO \\
(ERFS)
\end{tabular}

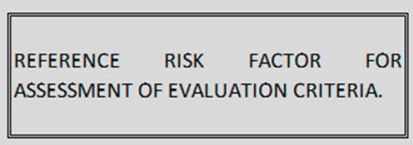

CRITICAL SCEINARIO (CERFS)

\begin{tabular}{|lrrr|}
\hline REFERENCE & SCENARIO & FOR \\
PERFORMANCE & EVALUATION & OF & THE \\
BUILDING EMERGENCY & RESPONSE \\
ORGANIZATION. & \\
\hline
\end{tabular}

REFERENCE SCENARIO FOR ANALYSIS OF THE PERFORMANCE PROFILE OF PUBLIC EMERGENCY RESPONSE ORGANIZATIONS FOR BUILDING FIRE RISK ASSESSMENT.

Fig. 14 Emergency response fire scenarios generated by PEFIRA

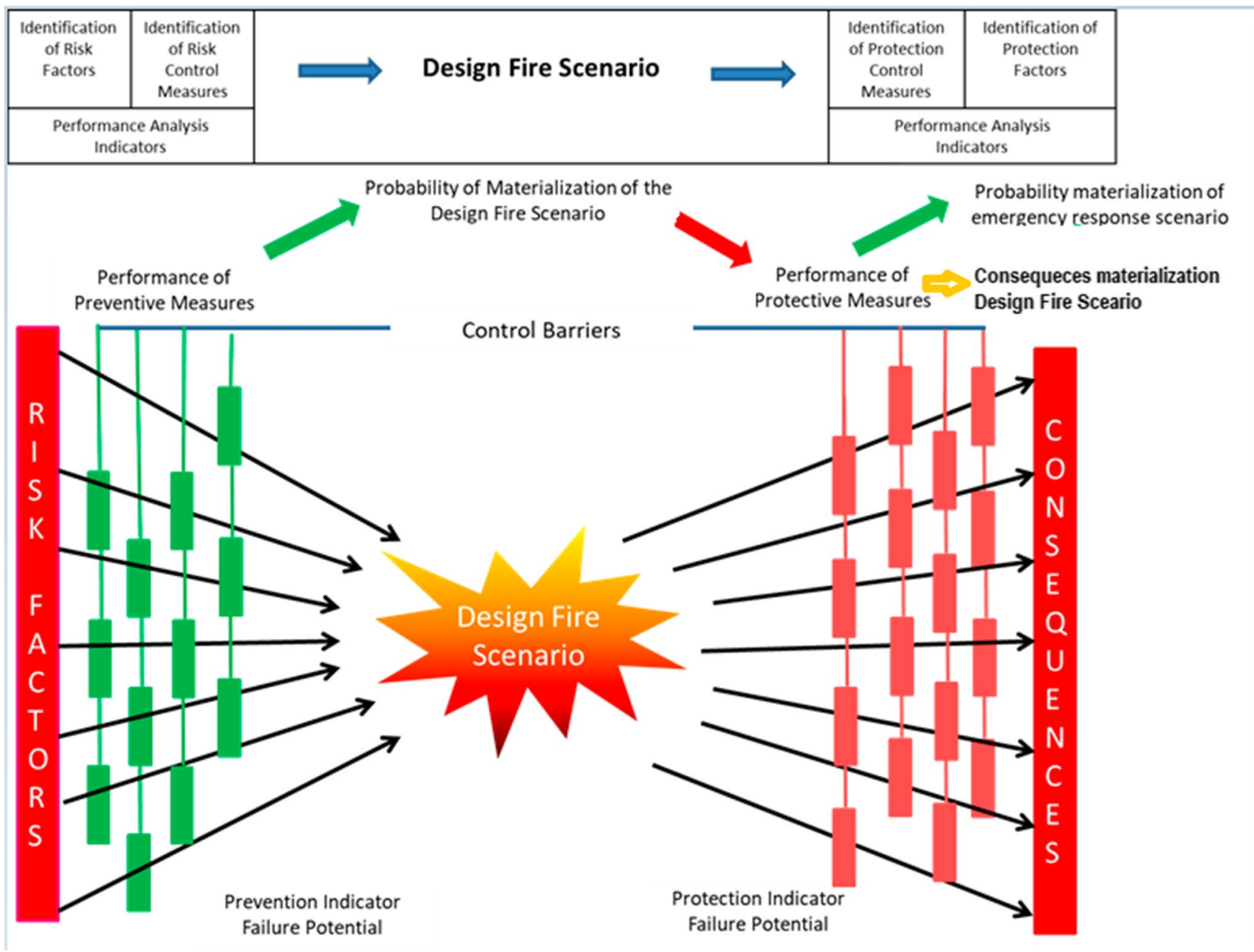

Fig. 15 Process for determining the risk of materialization of the design fire scenarios 
such as the limits of sustainability of life in the building or the limits for a safe evacuation of the building.

Although a single mathematical relationship is sometimes used to describe the fire growth, the duration and certainty of this growth inside the compartments can be very different due to fuel differences, ventilation conditions and compartment configuration. So it is easier to fully understand this process by targeting it in six growth regions.

As each region has a set of factors that dominate its behavior within its fire segment, it seems to configure a valid option to better analyze the details of its evolution and its interconnections. Using the same principle of analysis, PEFIRA models the potential fire growth, for the hypothesis of the presence of an effective ignition source, taking into account the factors that most contribute to each of the four stages of fire development that are shaded in Fig. 16. On the other hand, Interactive Performance Diagrams (IPD) are used, that demonstrate from each of the project fire scenarios, the relationship between the potential of fire growth, the performance of the building and the consequent response to its occupants (Fig. 14).

The first stage (E1) allows to analyze the process that determines the fuel conditions that enhance the ignition of the fire. The second stage (E2) allows to analyze the process of fire growth to the established combustion, corresponding to a representative fire of about $50 \mathrm{~cm}$ in height and $25 \mathrm{~kW}$ of power, being the upper limit of this segment represented in the respective IPD by a fire condition located at the point of origin as it is an incipient fire. The third stage (E3) allows to analyze the process of fire growth up to the designated ceiling point, corresponding this to a representative fire of about $250 \mathrm{~cm}$ in height and $1000 \mathrm{~kW}$ of power, being the upper limit of that segment represented in the respective IPD by the condition of fire developing in the compartment of origin. The fourth stage (E4) allows to analyze the process of fire growth up to the flashover (simultaneous ignition of all the combustible contents existing in the compartment), being the upper limit of this segment represented in the respective IPD by the condition of the compartment, if it is fully engulfed in fire.

Assuming that the fire growth is not affected by the configuration of the compartment up to the designated enclosing point, the model analyzes the potential evolution of stages E1 and E2 (i.e. the fire growth time to the designated established combustion point where it is considered that the fire reaches a power of about $25 \mathrm{~kW}$ or a flame height of about $0.5 \mathrm{~m}$ ) only on the basis of the conditions of fuel contents that enhance the fire ignition and the conditions for its self-sustain. The fire risk factors in this phase of analysis are the (1) flammability of the fuel agglomerates (group of fuels whose separation is so small that allows the rapid fire spread through them - combustible materials with less than $0.60 \mathrm{~m}$ of separation between them) origin of the ignition, (2) degree of division of the fuel agglomerates of origin of the ignition and (3) continuity of the surface of the fuel agglomerates of origin of the ignition (continuity of the surface of the fuel agglomerate in the three spatial dimensions for the purpose of flame spread-for example the flame spread on a carpet that is in the horizontal position is slower than if the same is in the upright position).

The model analyses the fire growth in stage E3 (i.e. the growth time of the fire to the designated ceiling point where the fire is considered to reach a power of about $2,000 \mathrm{~kW}$

Fig. 16 Fire growth stages

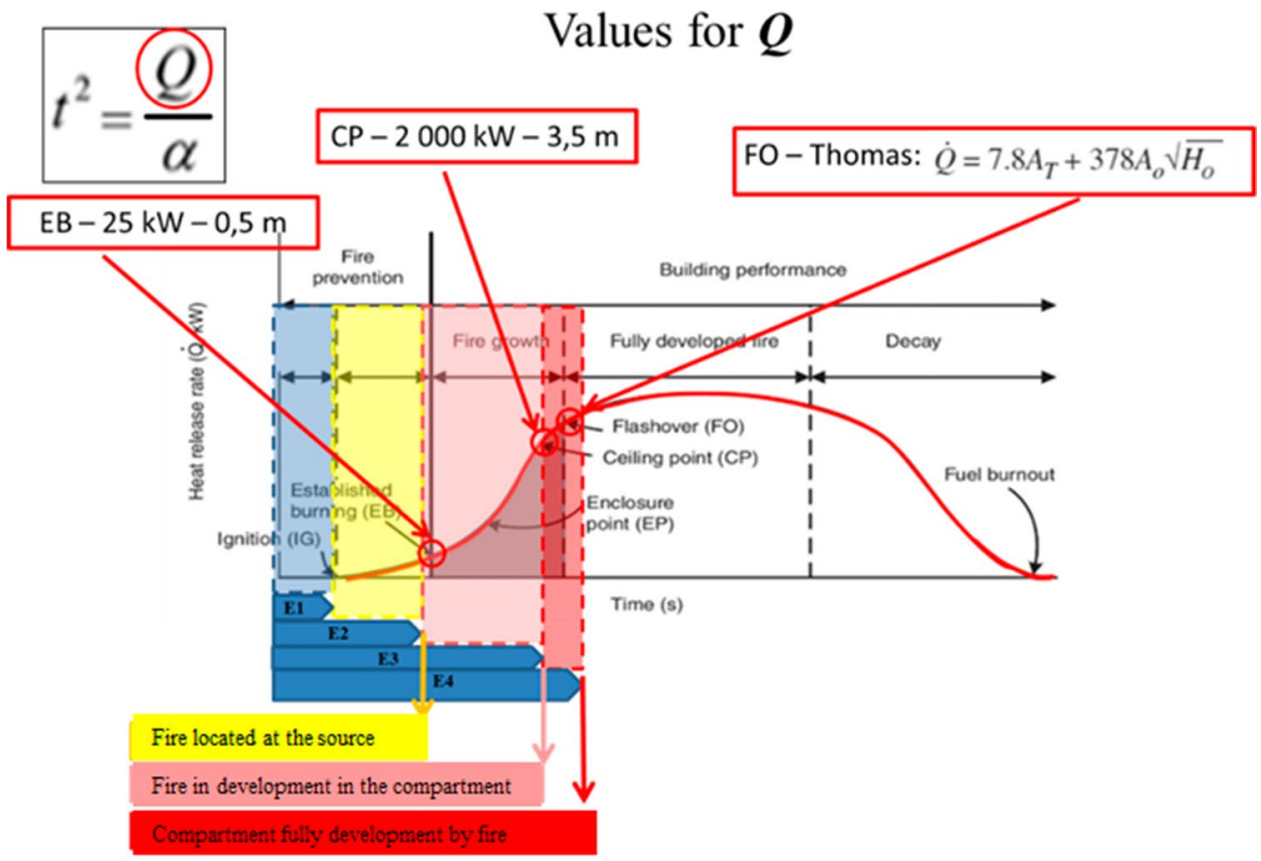


or flame height of about $3.5 \mathrm{~m}$ ), based on the risk factors of the previous stages and the (1) ceiling height and location of the fuel agglomerate origin of the ignition in relation to the ceiling and walls, as well as the (3) fire reaction interior cladding materials. The fire risk factors integrated in the analysis are the ones that most contribute to the flame growth process until the flames consistently hit the ceiling.

The model analyzes the fire growth in stage $\mathrm{E} 4$ (i.e. the growth time of the fire up to the designated flashover point, where the fire is considered to reach a power given equivalent to the Thomas formula) [23], based on the risk factors of the previous stages and the (1) thermal inertia of the existing fuel agglomerates in the fire compartment, (2) arrangement (distance) of the combustible agglomerates in the fire compartment, (3) volume of fuel content in the compartment and the volume of the compartment and (4) the opening factor of the compartment that influences the ventilation.

For estimating and modeling the increasing rate of the fire, the model uses the formulas presented in Fig. 16. In this Figure they are also defined the $Q$ values considered for the upper limits of each stage of the fire development. $\alpha$ can assume the values of Table 10 which are determined from the condition installed in the building in relation to the risk factors mentioned in the last paragraph (values 1 to 4). These risk factors when have a minimum potential of fire growth, they assume the value of 1 (lower limit of the evaluative scale), eliminating in this case the possibility of the fire developing for the following stages. When these risk factors have a maximum potential of fire growth they assume the value of 4 (upper limit of the evaluative scale), existing in this case a maximum potential for fire growth and spread.

In addition to model the potential of fire growth in the origin compartment, PEFIRA allows it to do so beyond it, analyzing the potential effect of dominoes between compartments from the risk factors of the previously mentioned stages of fire development existing in the compartments covered by the risk analysis.

For analyzing the performance of the evacuation process installed in the building the model assumes the time of fire growth up to the ceiling point as a time limit for a safe evacuation of the compartment(s) under analysis, considering this time as the time available for egress (ASET). On the other hand, the model determines the time required for safe egress (RSET) from the time of alarm detection, premovement time and travel time (Fig. 17).
PEFIRA also uses Interactive Performance Diagrams (IPD), in which a set of data is graphically processed to help taking decisions regarding the control of fire risk in existing buildings or the validation of alternative fire engineering solutions in buildings in the design phase.

The IPD allows also the establishing of Critical Zones of Analysis $(\mathrm{Z1}, \mathrm{Z2} \ldots \mathrm{Zn})$ about the interactivity between the performance of the building's fire safety system in the face of its design fire scenario. Figure 18 shows that $\mathrm{Z} 1$ allows analyzing the performance of the automatic sprinkler system and the occupants of the building in the face of fire, easily verifying that the wider the $\mathrm{Z} 1$, the more likely the system installed in the building will safely extinguish the fire before it reaches the established combustion. Z2 allows to analyze the performance of the internal emergency response team, and the wider the Z2, the more likely the system is to extinguish the fire, until the flames reach the ceiling point. Z3 allows to analyze the performance of the public fire services, and the wider this area is, the more likely is to extinguish the fire before hitting the flashover. Z4 allows to analyze the performance of the evacuation system of the building, and the wider the area is the more likely the system is to ensure the safe evacuation of the building.

\section{Fire risk components}

PEFIRA methodology takes into account a number of critical components that are considered as necessary to ensure a reliable fire risk assessment. PEFIRA works with the performance action domains described in the following sections.

\section{Potential of fire ignition}

Potential of Fire Ignition is a PAD of the Fire Prevention Index $\left(\mathrm{I}_{\mathrm{PREV}}\right)$. This parameter is as more critical to fire risk as more effective the ignition sources at the energetic level, lower the ignition temperature of the existing combustibles and more reactive the substances with oxidizing or catalyzing characteristics are. The parameter is further augmented in the presence of certain interactions between the ignition sources and the fuels (Fig. 1). PEFIRA assesses the ignition potential and fire development by analyzing the following 3 PCA: Ignition Source Conditions (PCA1), Fuel Conditions (PCA2) and Oxidizer Conditions (PCA3).

Table 10 Values of $\alpha$

\begin{tabular}{llllllll}
\hline UF & EF & VF & FA & ME & SL & VS & ES \\
\hline 0.190 & $0.120-0.060$ & 0.047 & $0.038-0.030$ & $0.021-0.012$ & $0.008-0.003$ & $0.0025-0.0020$ & $0.0015-0.0010$
\end{tabular}

UF-Ultra Fast; EF - Extremely Fast; VF - Very Fast; FA-Fast, ME-Medium; SL-Slow; VS-Very Slow; ES - Extremely Slow 
Fig. 17 Methodology for determining the Available Time for Safe Evacuation (ASET)
Detection and alarm time

Pre-movement time

Evacuation route:

Distance in plane<smiles>[CH+]1CCC1</smiles>

Distance up stairs<smiles>[CH]1C=CC1</smiles>

Distance down stairs

\begin{tabular}{r|r}
\hline $\mathrm{m}$ \\
$\mathrm{F}$
\end{tabular}

Flow density

High density

Nature of the occupants

Bedridden

Travel time

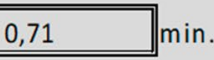

RSET
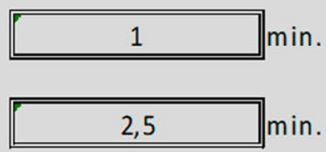
. 
equipment outside normal hours of building activity (PAI 6 ), thermal risk factors for indoor or outdoor ambient (PAI 7), potential risk factors resulting from lightning (PAI 8) and risk factors for potential sources of ignition originated outside the building (PAI 9).

\section{Fuel conditions}

PCA of Fuel Conditions is as more critical as lower the ignition temperatures of the combustible substances in the building are. In general, ignition of a fuel requires that temperature is sufficiently high to induce self-sustaining chemical reactions, time is sufficient high for energy absorbed by the reactants to cause the chain free radical formation and there is an adequate mixing between the reagents, so that the heat release is transmitted to them, allowing the reaction to proceed in a self-sustaining manner [24]. Other aspects analyzed in this PCA are those that may contribute to the fast growth of fire spread.

Thus, this PCA allows to analyze the following 8 PAI: existing of combustible substances ignition and fire-spread enhancers (PAI 10), combustible contents in hazardous places in the building (PAI 11), existing of combustible substances with potential to affect evacuation routes or emergency exits (PAI 12), control measures of combustible substances during the activities developed in the building (PAI 13), discontinuity of existing surfaces and combustible contents existing in the building (PAI 14), isolation and signaling of containers, storage reservoirs and combustible gas and/or liquid distribution systems (PAI 15), conditions for control and neutralization of combustible substances spills (PAI 16), factors of risk related to combustible substances outside the building (PAI 17).

\section{Oxidizer conditions}

PCA of Oxidizer Conditions is as more critical to fire risk as more favorable the air supply conditions to fire or more effective the ventilation of the spaces are. This component is especially critical in cases when oxygen enriched atmospheres inside buildings due to oxygen leakage or other oxidizing substances appear. Oxygen rich atmospheres are those in which the concentration of this gas is higher than $21 \%$ by volume or where the partial pressure of oxygen is higher than $21.3 \mathrm{kPa}$ or when both circumstances occur [25]. According to the National Fire Protection Association (NFPA) [26] an oxidant is a substance that easily produces oxygen or other oxidizing gas or promptly reacts to initiate the combustion of the combustible material and undergoes a vigorous self-sustaining decomposition due to contamination or heat exposure. An oxidizing agent when combined with a fuel may lead to a combustion process [27].
This PCA allows to analyze the following 4 PAI: existing of oxidizing substances or combustion catalysts (PAI 18), potential for oxygen rich atmospheres formation (PAI 19), sate of conservation and use of combustion catalysts or oxidizing substances (PAI 20) and control, isolation and signaling of containers and reservoirs and systems of combustion catalysts or oxidizing substances (PAI 21).

\section{Potential of working place}

The PAD of Potential of Workplace is part of the Fire Prevention Index $\left(\mathrm{I}_{\mathrm{PREV}}\right)$. It is as more critical to fire risk as higher the lack of organization of the workplace or less effective the organizational structure that controls the activities carried out in the working place (Fig. 17). PEFIRA assesses the working place potential by analyzing the following 3 PCA: fire safety program (PCA 4), quality of the management of activities carried out (PCA 5 ) and capacity of management of the occupied spaces (PCA 6).

\section{Fire safety program}

PCA of Fire Safety Program is as more critical as higher the fire risk profile of the building. The effectiveness of a fire safety program should be evaluated by its quality, accuracy, usefulness and impact produced from the highest to the lowest level of the organization [28].

This PCA analyzes the following 6 PAI: fire safety program/dossier (PAI 22), formally established fire safety framework (PAI 23), management model of the fire safety program/dossier (PAI 24), system and procedures of fire risk management (PAI 25), control of fire safety reports and records (PAI 26) and exigency of internal inspections and audits for periodically evaluating the fire safety program (PAI 27).

\section{Management of activities}

PCA Management of Activities is as more critical to fire risk as higher the dysfunctionality of the organization and activities developed in the building and lower the standardization of procedures and production processes.

This PCA analyses the following 5 PAI: formal organization of the work (PAI 28), standardized methods of work (PAI 29), fire risk factors imposed by productive processes (PAI 30), work instructions with existing equipment and systems (PAI 31) and formal control over the quality and safety relating to the working methods and production processes (PAI 32). 


\section{Management of occupied areas}

PCA related to Management of Occupied Areas is as more critical to fire risk as higher the lack of cleanness and tidiness of places or less effective the processes for controlling their use and maintenance are.

This PCA allows analyzing the following 4 PAI: organizing and control of places (PAI 33), conditions of packing and storage of goods (PAI 34), control of permanent nonoccupied places (PAI 35) and physical and chemical incompatibility in production, handling and transport of goods/ materials/substances (PAI 36).

\section{Potential of human resources}

Potential of Human Resources is a PAD that is part of the Fire Prevention Index ( $\left.\mathrm{I}_{\text {PREV }}\right)$. In general, this action domain is as more critical to fire risk as higher the lack of preparedness of building occupants regarding to safety in the developed activities and less is the promotion and the installed capacity in the organization to inform and train the building occupants on fire safety (Fig. 1). PEFIRA assesses the Potential of Human Resources by analyzing the following 3 PCA: management of people and skills in fire safety (PCA 07), information and dissemination of the fire safety program (PCA 08) and management of fire prevention (PCA 09).

\section{Management of people and skills}

PCA related to the Management of People and Skills is as more critical to fire risk as more inadequate the selection and training policies of building occupants and lower the building occupants' skills on fire safety procedures are. The training policy is not justified by itself but by the contribution to the efficiency of the organizations, not being an isolated activity, but an element of a global process of management and development of the human resources [29]. The suitability of the training depends on a correct and constant diagnose of training needs [30].

This PCA allows to analyze the following 7 PAI: selection process of people to the fire safety functions (PAI 37), suitability and effectiveness of the organization for fire safety training of people (PAI 38), management of fire safety training (PAI 39), skills of building occupants in terms of fire safety (PAI 40), syllabus and duration of fire safety courses (PAI 41), system of assessment of the effectiveness of the fire safety training courses (PAI 42) and management processes of practical exercises in fire safety (PAI 43).
Information and dissemination of the fire safety program

PCA of Information and Dissemination of Fire Safety Program is as more critical to fire risk as less efficient is the fire safety information and communication policies and less efficient the means for their dissemination. In this parameter it is important the institutional communication and involvement of the main responsible, depending on the size of the company and budget used in the process.

This PCA allows the analysis of the following 5 PAI: management of fire safety information and communication (PAI 44), safety and emergency signaling (PAI 45), disclosure and dissemination of the emergency plans (PAI 46), disclosure of the fire safety plan (PAI 47) and disclosure of documents and safety data sheets of the existing hazardous substances and goods (PAI 48).

\section{Management of fire prevention}

The Management of Fire Prevention is a PCA that depends a lot on the fire prevention plan and procedures and their implementation.

This PCA allows to analyze the following 8 PAI: fire prevention plan/procedures (PAI 49), process for identifying, reporting and control of fire risk factors (PAI 50), formal assignments in the scope of fire prevention (PAI 51), implementation and control of operating procedures of the critical fire safety systems and equipment (PAI 52), implementation and control of the operating procedures of the places (PAI 53), fire prevention measures in the activities and production processes (PAI 54), control and treatment of faults related to fire prevention (PAI 55) and assessment and review of the fire prevention plan/procedures (PAI 56).

\section{Potential of equipment and systems}

Potential of Equipment and Systems is a PAD that is part of the Fire Prevention Index ( $\left.\mathrm{I}_{\text {PREV }}\right)$. It is an action domain that gains relevance to fire risk with the increasing number of equipment and systems installed in the building, making the quality of the maintenance programs and process a very important issue (Fig. 1). PEFIRA assesses the following 3 PCA: conditions of the technical installations (PCA 10), management of the maintenance (PCA 11) and system of control of maintenance and safety records (PCA 12).

\section{Technical installations conditions}

This PCA is as more critical to fire risk as higher is the installed power in the building and the time/regime of use 
the equipment in the building and the worst the conditions of their conservation and operation.

This PCA analyzes the following 6 PAI: suitability of technical structures, equipment and systems of support and scheme of use (PAI 57), project, design and certification of critical equipment and systems with potential to fire outbreak (PAI 58), project, design and certification of fire safety equipment and systems (PAI 59), state of conservation and working of fire safety equipment and systems (PAI 60), state of conservation and working of critical equipment and systems for fire safety (PAI 61) and state of conservation and operation of the building and technical installations (PAI $62)$.

\section{Management of maintenance}

Management of Maintenance is a PCA that becomes relevant to fire risk with the increasing of equipment, systems power supply installed in the building. One of the most important aspects for this PCA is the quality of the inspection, maintenance and testing program of the equipment. This PCA analyses the following 7 PAI: formal responsibility for the management of maintenance (PAI 63); program/dossier of maintenance of equipment and critical technical systems for fire safety (PAI 64), program/dossier of maintenance of fire safety equipment and systems (PAI 65), program/dossier of maintenance of the building and technical installations (PAI 66), control process of the maintenance (PAI 67), processes of consignment/lockout and signaling of power in equipment, systems and installations in maintenance (PAI 68), and authorization of hazardous work for performing the maintenance actions (PAI 69).

\section{Maintenance control and safety records}

PCA of Maintenance Control and Safety Records is as more critical to fire risk as higher the number of equipment, systems and power supply installed in the building. One of the aspects that contributes to this PCA is the effectiveness of the fault control and correction processes. This PCA analyses the following 5 PAI: existing of maintenance controls and critical occurrences (PAI 70), compliance and update of fire safety records (PAI 71); existing of formal records regarding consignment processes for equipment, systems and installations (PAI 72), existence of formal records regarding hazardous work permits (PAI 73) and existence of formal procedures and conditions to ensure the archive of the records for 10 years (PAI 74).

\section{Potential of fire spread}

Potential of Fire Spread is a PAD that is part of the Fire Protection Index $\left(\mathrm{I}_{\mathrm{PROT}}\right)$. The contribution of this domain of action to fire risk is higher as less effective the passive fire protection components contributing to the fire containment are (Fig. 1).

PEFIRA analyzes the following 4 PCA: fire barrier conditions (PCA 13), fire compartment ventilation conditions (PCA 14), fire resistance and reaction conditions (PCA 15) and fire brigades access to building conditions (PCA 16).

\section{Fire barrier conditions}

PCA of Fire Barrier Conditions is as critical to fire risk as larger the areas and volumes of the compartments and less efficient the conditions of physical barrier between compartments are. One aspect to take into account in this PCA is the potential rate of fire spread. There should be no confusion between combustion rate of a substance and fire spread rate [31]. While the combustion rate depends on the kinetics of a given oxidation-reduction reaction, in which is higher as higher the combustibility of the product is, the fire spread rate, although influenced by the rate of combustion of each existing substance, depends on factors such as the dispersion of the combustible products in the places and the barrier effect between these products. The amount of combustibles and the way they are disposed in the compartments have high influence on the fire spread [32].

This PCA analyzes the following 6 PAI: area of fire compartments (PAI 75), absence of fire resistance in the elements of the fire compartment (PAI 76), condition of multidirectional barrier to the potential interior of fire spread (PAI 77), potential of failure of passive fire barrier (PAI 78), project, design, and certification of the building technical equipment and systems (PAI 79) and condition of barrier against fire spread between buildings (PAI 80).

\section{Fire compartment ventilation conditions}

This PCA is as more critical to fire risk as higher the potential of ventilation of the fire compartment where the fire outbreaks. The mass loss rate and the heat release rate in a fire are proportional to the ventilation factor of the compartment where the fire starts, being this factor determined by the product of the area of the opening by the square root of the height of the fire compartment [33]. The ventilation potential that influences the severity of a fire in the compartment is as more critical as higher the area of the openings in the fire compartment is. In this analysis it is considered that the breaking temperature of a current glass is around $150^{\circ}$ $\mathrm{C}$ and the softening temperature is $400^{\circ} \mathrm{C}$ [34].

Thus, this PCA analyzes the following 3 PAI: air supply to the fire (PAI 81), condition of glazing surface in compartment's walls (PAI 82), and condition of project and design of the ventilation and air conditioning systems (PAI 83). 


\section{Fire resistance and reaction conditions}

This PCA of Fire Resistance and Reaction is as critical to fire risk as worst the intrinsic fire risk factors of the building and worst the fire resistance of the compartmentation elements and the fire reaction characteristics of the building materials are. A fire safe building can be defined as the one where there is a high probability of all occupants surviving from a fire without injuries and where the damages to property are confined to places in the vicinity of the fire [35].

Thus, this PCA analyses the following 7 PAI: conditions of fire resistance of building walls, floors and roofs (PAI 84), conditions of fire resistance of building structural elements (PAI 85), conditions of isolation and protection of the escape routes (PAI 86), conditions of protection and isolation of the general fire compartmentation (PAI 87 ), conditions of isolation and protection of hazardous locations (PAI 88), conditions of isolation and protection of interior openings in the fire compartments (PAI 89) and fire reaction of the coating materials (PAI 90).

\section{Fire brigade access to building conditions}

This PCA is related to the conditions of Fire Brigade Access to the building and is as more critical to fire risk as more difficulties on the access to all facades of the building and more difficulties to the entrance of fire fighters in the building for rescuing and firefighting exist. The potential to fire spread is dependent on the number of entrances and ways to enter in the building for the fire brigade. Thus, this PCA analyzes the following 4 PAI: condition of existing access routes in the building for rescuing and firefighting (PAI 90); conditions to enter in the building for rescuing and firefighting (PAI 91), condition of part of the building envelope being available for rescuing and firefighting (PAI 92) and conditions of organization, maintenance and permanent operation of the access routes and entrance points in the building for firefighters (PAI 93).

\section{Potential of fire damage}

This PDA is part of the Fire Protection Index $\left(\mathrm{I}_{\mathrm{PROT}}\right)$ and is as critical to fire risk as lower the potential of protection of the fire load and corrosive smoke released by the combustion of the building products (Fig. 1). PEFIRA assesses this PAD by analyzing the following 4 PCA: protection from the fire load effects (PCA 17), protection from the products of combustion effects (PCA 18), protection to fire exposure (PCA 19) and protection to unlawful acts (PCA 20).

\section{Protection from fire load effects}

This PCA is as more critical to fire risk as higher the modified fire load in the places of storage and packing of goods, its concentration in the places and less efficient the installed automatic fire extinguishing systems are.

This PCA analyzes the following 5 PAI: modified fire load in the fire risk places of the building (PAI 95), condition of fire load of building property (PAI 96), agglomeration of modified fire load in the building (PAI 96), existing of automatic fire extinguishing systems in places of increased fire risk (PAI 97) and conditions of storage of combustible products (PAI 98).

\section{Protection from combustion products effects}

PCA of Protection to Combustion Products is as more critical to fire risk as more harmful to life, construction elements and building contents the products of combustion released and less effective the protection means to its action are. The characteristics and density of the smoke, as well as the hazardousness of the substances released in the burning of the building products are of outmost relevance in this analysis.

This PCA analyses the following 4 PAI: condition of combustible products with significant potential for releasing heavy smoke and hazardous products in case of fire (PAI $100)$, condition of smoke cleaning in places of high fire risk (PAI 101), condition of extraction of combustion effluents from the burning of existing appliances and equipment (PAI 102) and condition of pollution of indoor ambient protection systems (PAI 103).

\section{Protection to fire exposure}

PCA of Protection to Fire Exposure is as more critical to fire risk as higher the potential of exposure of the building occupants and consequently shorter the distances of them to places of high fire risk are. In this context, the fire exposure concept is understood as the condition of building occupants being directly and immediately exposed to the thermal effects of a fire.

It should be noted that the transfer of radiated energy between surfaces depends on their geometry, orientation, temperature and radiation properties, being the geometry and orientation of each of these surfaces taken into account in the calculations using one or more configuration factors, usually called as view, shape, angle or geometric factors [36, 37]. According to [38] the heat absorbed by a surface depends on the: i) size and configuration of the flames; ii) temperature of the flame surface; iii) heating of the atmosphere due to fire travelling to the target surface (surface of the element/object/material exposed to the fire) and iv) size and orientation of the target surface. The time 
for occurring a second degree burn, with the skin at an initial temperature of approximately $32.5{ }^{\circ} \mathrm{C}$, can be correlated with the intensity of the radiation. The acceptable value for direct exposure of humans to thermal radiation is $5 \mathrm{~kW} / \mathrm{m}^{2}$ [39].

This PCA analyses the following 5 PAI: protection of persons from fire hazard locations (PAI 104), protection of evacuation routes from fire hazard locations (PAI 105), protection of systems and structures vital to business activity and labor continuity from fire hazard locations (PAI 106), fire protection in high fire risk places (PAI 107), and safety clearance and isolation of storage places of combustible liquids and gases (PAI 108).

\section{Protection to unlawful acts}

PCA of Protection to Unlawful Acts is as more critical to fire risk as higher the possibility of the building and its occupants being subjected to an unlawful act, such as arson or terrorist attacks, and lower the possibility of establishing an effective control of accesses and surveillance in the interior of the places. In these cases, one of the aspects that reduces fire risk is the existence of conditions for effective control to unauthorized accesses and permanent monitoring of public spaces. Analyzing the US Annual Report on Fire Statistics [40] it can be seen, for example, that fires of intentional acts, by their nature, tend to cause higher human and material damages, thus justifying by this their inclusion in the fire risk analysis process. The threat potential depends on various aspects such as the type of activity, importance of the products and services produced, the socio-economic market context or the characteristics of the place itself.

Thus, this PCA analyzes the following 5 PAI: potential of threat to illicit acts (PAI 109), physical security program against premeditated or negligent acts (PAI 110), condition of control to unauthorized accesses (PAI 111) condition of surveillance system and immediate reaction to unauthorized accesses (PAI 112).

\section{Potential of building evacuation}

This PDA is part of the Fire Protection Index $\left(\mathrm{I}_{\mathrm{PROT}}\right)$ and depends strongly on the existing constraints to evacuation, awareness and training of building occupants and the potential of some protection of the evacuation routes (Fig. 1). PEFIRA assesses this PDA by analyzing the following 4 PCA: condition of efficiency of the alarm systems in the evacuation process (PCA 21), conditions of smoke opacity and toxicity (PCA 22), conditions of smoke control on escape routes (PCA 23) and condition of efficiency in the management of evacuation (PCA 24).

\section{Alarm and evacuation conditions}

The Alarm and Evacuation conditions is a PCA that is in general more critical to fire risk as less efficient to the physical conditions for evacuation, more complex the building and longer the evacuation paths to travel until reaching outside or a safe place are. In this particular situation, the dimensions, number of exits and complexity of the places are of outmost importance for this PCA.

In the fire risk analysis, it is important to understand the concept of protecting occupants "not hindered" to the fire. A common example of fire hindering is a person engulfed in a bed or sofa fire originated by him/herself [41]. The strategy of analysis related to the means of evacuation existing in the building should take into account the risk factors whose occurrence is reasonably expected throughout the life of the building.

This PCA analyzes the following 7 PAI: conditions of fire detection and alarm (PAI 113), conditions of maintaining the evacuation capability in face of the potential factors of the identified risks (PAI 114), conditions of location and number of emergency exits for evacuation of risk places in the building (PAI 115), conditions of safety signaling and emergency lightening (PAI 116), conditions of design of evacuation routes and emergency exits (PAI 117), conditions of evacuation routes and distances to travel (PAI 118) and conditions of refuge areas (PAI 119).

\section{Opacity and toxicity of combustion products}

Opacity and Toxicity of Combustion Products is as more critical to fire risk as higher the potential for smoke and toxic gases released in the combustion of the building products and materials in case of fire is. The statistical evidences show that most of the fatalities caused by fires are not resulting of the direct exposure to flames but due to the inhalation of smoke and toxic gases. The effects of smoke and toxic gases on people during building evacuation may result from i) decreasing of visibility in the compartments and evacuation routes, ii) respiratory irritation, coughing and suffocation, iii) increasing of respiratory and heart rate due to carbon dioxide, iv) decreasing of physical and psychological capacity of the occupants in evacuation and v) panic due to loss of orientation caused by the imminent need to evacuate the building.

This PCA analyses the following 3 PAI: potential of toxicity and opacity of the combustion products in the building in case of fire (PAI 120), condition of height and volume of places and evacuation routes for dissipation of smoke and maintenance of a smoke-free height required for evacuation (PAI 121) and potential blocking of emergency exits and evacuation routes (PAI 122). 


\section{Smoke control in escape routes}

This PCA is as more critical to fire risk as lower the installed capacity in terms of ventilation and smoke control systems in face of the building's intrinsic fire risk factors is. It is important to have a consistent strategy to the smoke control systems in the evacuation routes and smoke exhaustion of places of high fire risk.

This PCA analyses 4 PAI: existing of smoke control systems in the evacuation routes (PAI 123), Condition of project and test of the smoke control systems in the evacuation routes (PAI 124), Conditions of switching on and autonomy of working of the smoke control systems in the evacuation routes (PAI 125) and condition of efficiency of the smoke control systems (PAI 126).

\section{Management of evacuation}

This PCA is as more critical to fire risk as higher the intrinsic fire risk reference factors of the building, as for example the building height, the number of occupants or the fire load density of the building, are. The complexity of the evacuation planning depends on the fire risk profile of the building and can assume in a simplified way the evacuation procedures or in a most complex way the formal evacuation plan. Independently of this complexity, there should be evidences at a theoretical and practical level that in case of fire the building is evacuated in a safe, effective and rapid way.

This PCA analyses the following 3 PAI: condition of existing and efficacy of plan / procedures of evacuation (PAI 127), condition of implementation of the evacuation plan / procedures (PAI 128) and condition of training and evaluation of evacuation procedures (PAI 129).

\section{Potential of emergency response}

The Potential of Emergency Response is a PAD that is part of the Protection Index $\left(\mathrm{I}_{\mathrm{PROT}}\right)$. In general, this domain of action is as critical to fire risk as less effective the active fire protection equipment installed in the building and the capability of the building occupants and the public fire brigades to respond in case of fire are (Fig. 1).

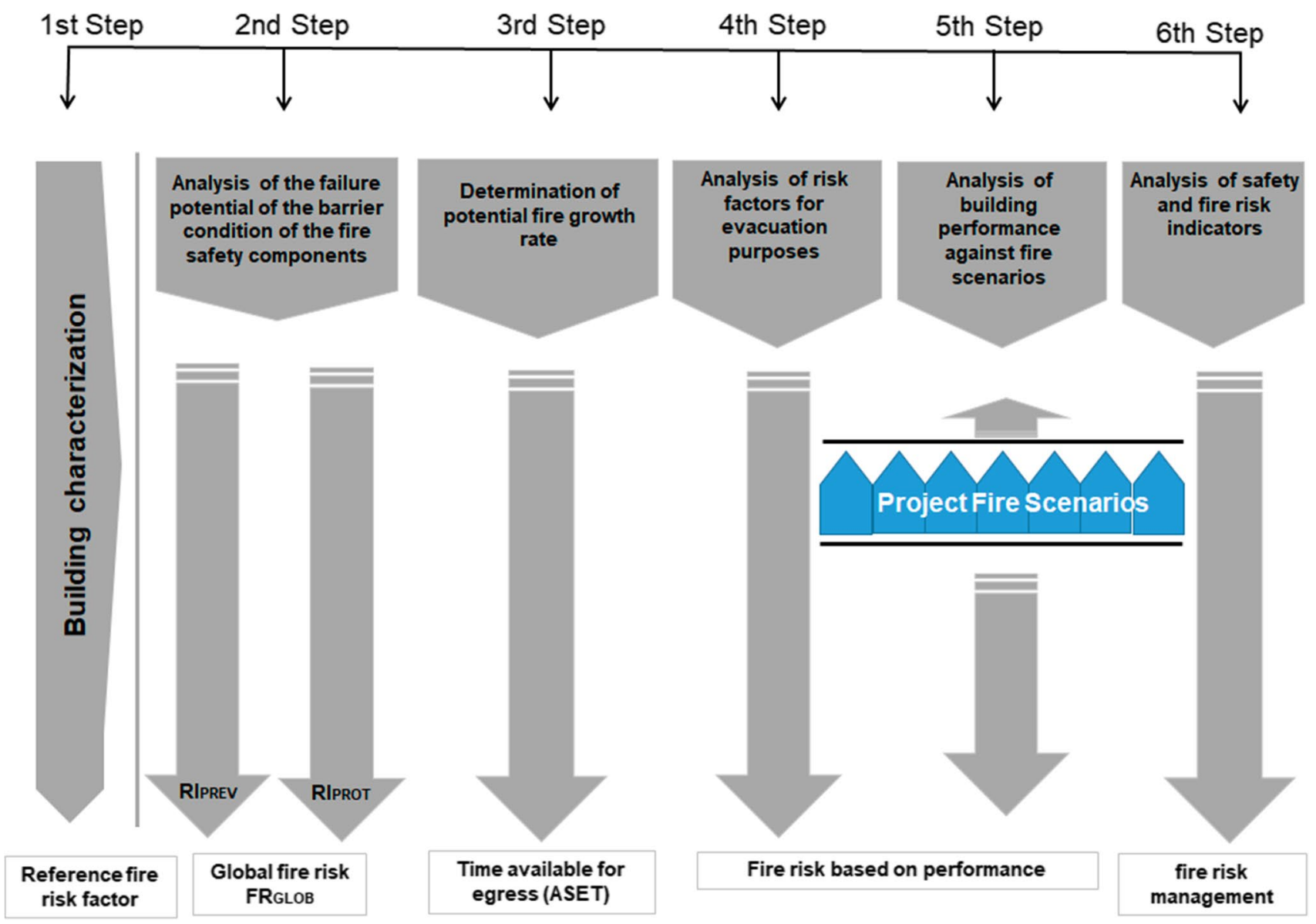

Fig. 19 PEFIRA application flowchart 
PEFIRA assesses the Potential of Emergency Response by analyzing the following 4 PCA: condition of the fire safety equipment and systems installed in the building (PCA 25), management of emergency (PCA 26), emergency response capability installed in the building and public fire brigades to respond to fire (PCA 27) and resources available for emergency response (PCA 28).

\section{Fire safety equipment and systems}

Fire Safety Equipment and Systems is as more critical to fire risk as lower the capacity and effectiveness of the active fire safety systems installed in the building are. The most effective way to guarantee permanently an immediate action on controlling fire in the early stages and thus reducing the potential of failure of this PCA is the existence of automatic and manual fire extinguishing means such as sprinklers, extinguishers and fire hydrants.

This PCA allows the analysis of the following 7 PAI: condition of existing automatic fire extinguishing systems (PAI 130), condition of design and installation of automatic fire extinguishing systems (PAI 131), condition of existing manual fire extinguishers (PAI 132), condition of design and installation of manual fire extinguishers (PAI 133), condition of availability and supply of extinguishing agents for fire extinguishing systems (PAI 134), condition of water availability for relief means (PAI 135) and condition of existing of automatic fire alert systems for external rescue entities (PAI 136).
Fig. 20 Characterization of the building

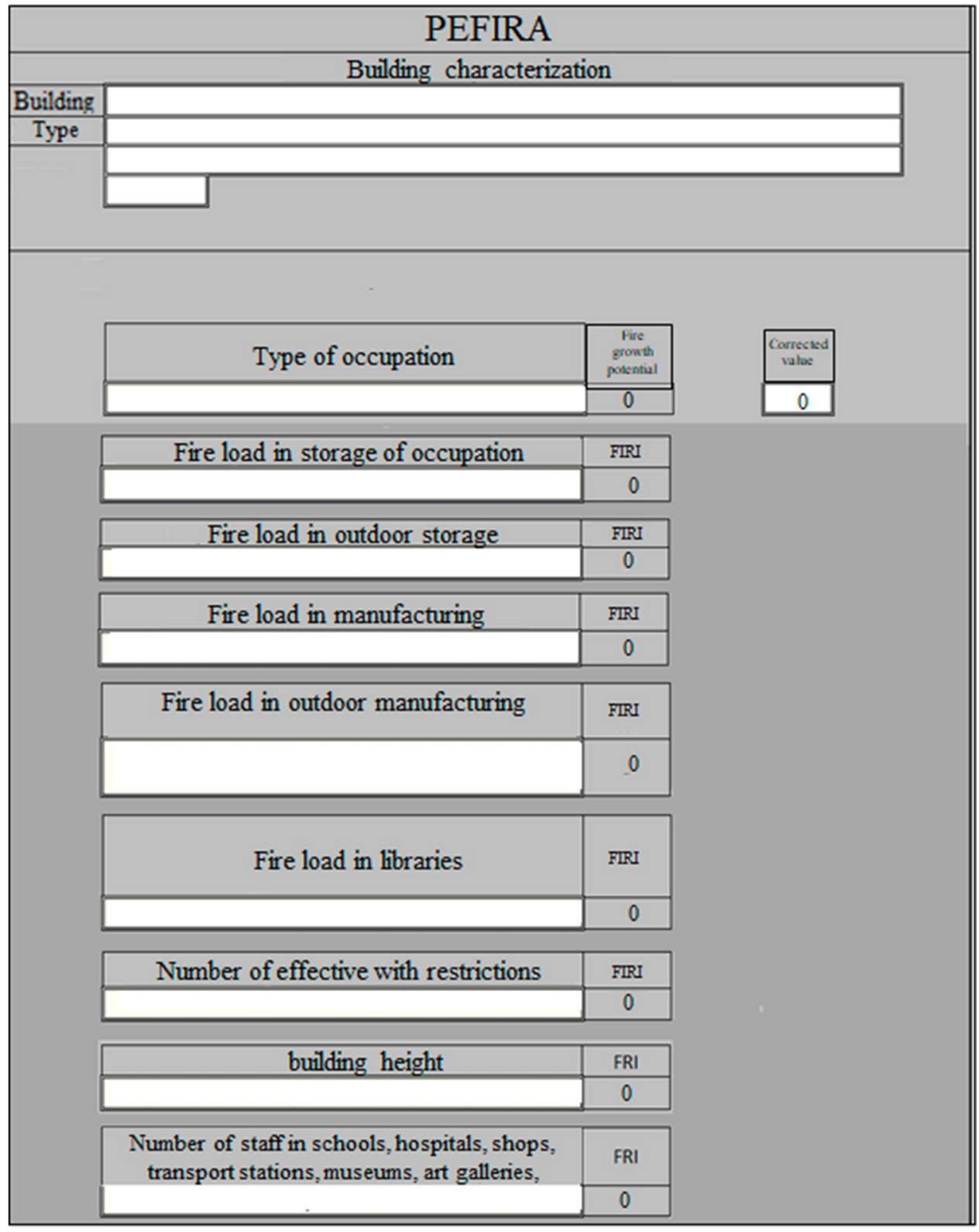




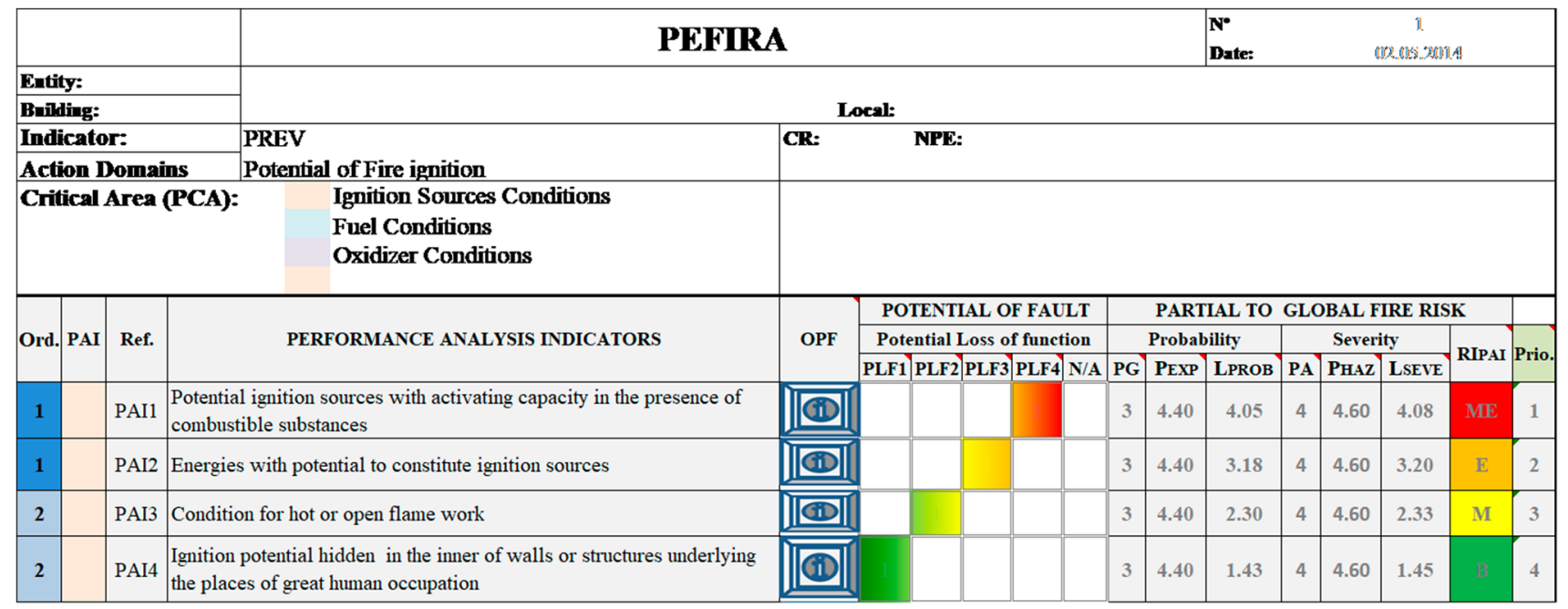

Fig. 21 - Methodology for operationalizing the performance analysis indicators

\section{Emergency response management}

The contribution of this PCA to fire risk is as relevant as higher the intrinsic risk factors to building, more complex the potential emergency scenarios and higher their expected magnitude to building are. A factor that has a great effect on the protection of life of the building occupants is the capability installed in the building and community to respond to fire. An emergency response should be based on organizational assumptions that can provide the basis for a clear communication and effective operational implementation [42].

This PCA analyses the following 9 PAI: condition of existing, adequacy and efficacy of the emergency plan/procedures (PAI 137), condition of implementation of the emergency plan/procedures (PAI 138), condition of suitability of all building occupants for immediate intervention in case of fire (PAI 139), condition of human resources for emergency response teams, taking into account the complexity and size of the building (PAI 140), condition of design and functionality of the internal organization for responding to the potential emergency scenarios (PAI 141), condition of leadership, command and control of the response to the potential emergency scenarios (PAI 142), condition of readiness and response times of the public fire brigades (PAI 143), condition of the operational resources of the public fire brigades (PAI 144) and condition of existing of a plan of standardizing and continuity of business operation (PAI 145).

\section{Emergency response capability}

Emergency Response Capability is a PCA that in general is as more critical to fire risk as higher the complexity of the selected fire scenarios and the expected impact on their

\section{Fire Risk Index (RIPCA)}

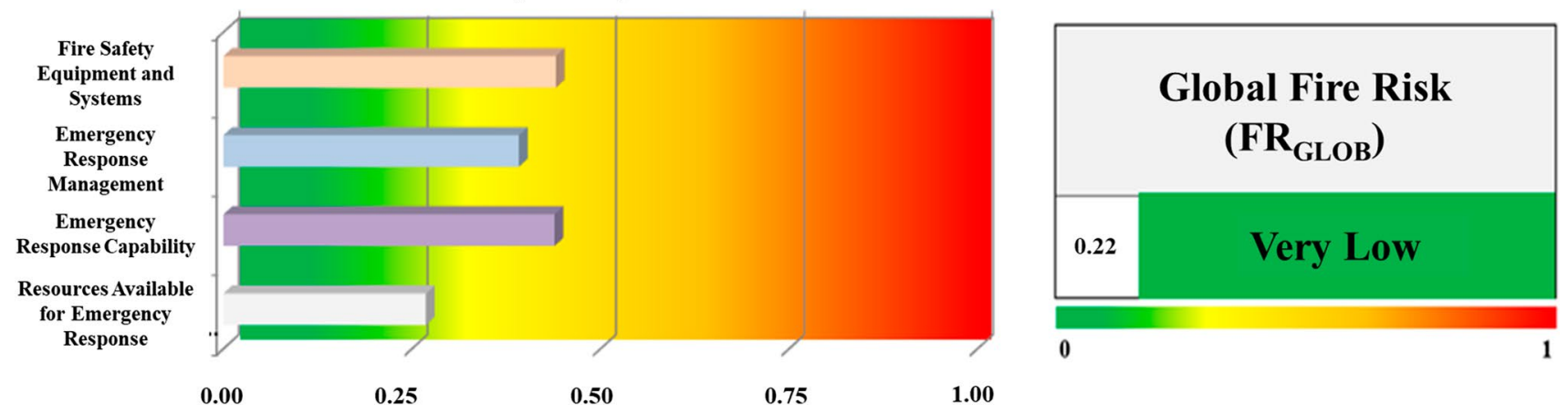

Fig. 22 Examples of partial and global fire risk indicators for the building 
materialization are. This capacity depends in large extent on the suitability and effectiveness of the emergency response organizations, and in particular on the available human resources, being commonly accepted that such organizations must have adequate capacity to fulfill their assigned tasks in the light of the fire scenarios. This PCA verifies if all reasonably foreseeable fire scenarios have been selected, if correspond to the risk factors that contribute to the building's vulnerabilities [43] and if the nature of the missions and the levels of intervention assigned to the internal emergency organization are adequate [44].

This PCA makes it possible to analyze the following 6 PAI: condition of internal control of the potential emergency scenarios in context of simulation (PAI 146), condition of internal organization of alarms, alerts and time response in context of simulation of the potential emergency scenarios (PAI 147), condition of operational management of the internal organization for emergency response in context of simulation of the potential emergency scenarios (PAI 148), condition of technical and operational preparation of the emergency response team members in the context of simulation of the potential emergency scenarios (PAI 149), condition of assistance to the victims in context of simulation of the potential emergency scenarios (PAI 150) and condition of response of external rescue means in context of simulation of the potential emergency scenarios (PAI 151).

\section{RISK FACTORS FOR DETERMINING FIRE GROWTH SPEED}

\begin{tabular}{|c|c|c|c|}
\hline $\begin{array}{l}\text { Flammability of the ignition source combustible } \\
\text { agglomerate. }\end{array}$ & \multicolumn{2}{|l|}{ Liquids with flash point below $38^{\circ} \mathrm{C}$} & 4 \\
\hline $\begin{array}{l}\text { Degree of division of the ignition source fuel } \\
\text { agglomerate (exposed area). }\end{array}$ & \multicolumn{2}{|c|}{$\begin{array}{l}\text { Liquid fuels thinly divided or solids with little thickness or } \\
\text { some division }\end{array}$} & 2 \\
\hline $\begin{array}{l}\text { Continuity of the surface of the fuel agglomerate } \\
\text { originating the ignition. }\end{array}$ & \multicolumn{2}{|c|}{$\begin{array}{l}\text { Continuity of the fuel surface in all directions in the } \\
\text { horizontal plane and in the vertical plane, relative to the } \\
\text { agglomerate of ignition origin }\end{array}$} & 4 \\
\hline $\begin{array}{l}\text { Ceiling height and location of the ignition-origin } \\
\text { fuel agglomerate in relation to the walls. }\end{array}$ & \multicolumn{2}{|c|}{$\begin{array}{l}\text { Fuel agglomerate located near the corner of a compartment } \\
\text { with a ceiling height of } 3 \mathrm{~m} \text { or less }\end{array}$} & 4 \\
\hline $\begin{array}{l}\text { Quantity and three-dimensional dimension of the } \\
\text { fuel agglomerate to reach the ceiling point.. }\end{array}$ & \multicolumn{2}{|c|}{$\begin{array}{l}\text { Altura do aglomerado combustivel superior a } 75 \% \text { da altura } \\
\text { do compartimento }\end{array}$} & 4 \\
\hline $\begin{array}{l}\text { Reaction to fire of the compartment's interior } \\
\text { linings. }\end{array}$ & \multicolumn{2}{|c|}{$\begin{array}{l}\text { Compartment lining materials with acceptable fire behavior } \\
\text { or higher of class D, E, F (flammable) }\end{array}$} & 4 \\
\hline $\begin{array}{l}\text { Thermal inertia ( } \mathrm{kpc} \text { ) of the combustible } \\
\text { agglomerates existing in the source compartment. }\end{array}$ & \multicolumn{2}{|c|}{$\begin{array}{l}\text { Low thermal inertia of most interior combustible coatings and } \\
\text { most combustible agglomerates in the compartment }\end{array}$} & 4 \\
\hline $\begin{array}{l}\text { Arrangement of fuel agglomerates in the area of } \\
\text { the original compartment. }\end{array}$ & \multicolumn{2}{|c|}{$\begin{array}{l}\text { Distance less than } 0.60 \mathrm{~m} \text { between fuels from the original agglomerate } \\
\text { with auto-ignition temperature between } 450^{\circ} \mathrm{C} \text { and } 350^{\circ} \mathrm{C}\end{array}$} & 3 \\
\hline \multirow{2}{*}{$\begin{array}{l}\text { Relation between the volume of original fuel } \\
\text { content and the volume of the compartment }\end{array}$} & Compartment volume (m3). & 100 & \multirow[b]{2}{*}{4} \\
\hline & Volume occupied by the fuel agglomerate (m3). & 80 & \\
\hline \multicolumn{3}{|c|}{ Opening factor in the compartment for ventilation effect. } & 1 \\
\hline
\end{tabular}

Fig. 23 Risk factors regarding the combustible contents existing in the building 


\section{Resources available for emergency response}

The Available Resources for Emergency Response is a PCA which relevance to fire risk increases as the building reference risk factor as well as the potential complexity and magnitude of the foreseeable fire scenarios for building increase. One aspect to bear in mind in the analysis process is that this PCA is highly conditioned by the selected fire scenarios for the building and consequently conditions of the skills to be developed by formation and training of the people.

This PCA analyzes the following 5 PAI: condition of existing and use of personal protective equipment by the safety teams in context of simulation of the potential emergency scenarios (PAI 152), condition of existing and use of equipment for emergency response in context of simulation of the potential emergency scenarios (PAI 153), condition of existing and use of communication equipment for emergency response in context of simulation of the potential emergency scenarios (PAI 154), condition of existing and use of victim protection and stabilization equipment in context of simulation potential of the potential emergency scenarios (PAI 155) and condition of existing and use of identification and support systems to the leadership and command bodies of internal emergency response in context of simulation of the potential emergency scenarios (PAI 156).

\section{Field of application of the fire risk analysis}

PEFIRA is a fire risk analysis methodology in development that has already been tested in several buildings with at least ten different use-types of occupation. Its use is intuitive and the application is made in stages. The sequential steps are represented in the flowchart in Fig. 19.

Step 1 Building characterization

The application of PEFIRA starts with the characterization of the building, which is based on the spreadsheet presented in Fig. 20, where is determined the reference fire risk factor (FRIR) of the building. FRIR determines the optimized fire barrier condition that will serve to analyze the potential for failure in the next step. The FRIR is determined as a function of the highest Intrinsic Fire Risk Factors (IFRF), explained in point 2.1.7.

Step 2 Analysis of the potential failure of the fire barrier condition

In this stage of application of the method, an analysis of the failure potential of the fire barrier condition of the SCI components is carried out, based on the Performance Analysis Indicators (IAD). The failure potential of each SCI component is determined by comparing the actual or potential performance of each of these components with the respective standard performance established as a function of the FRIR determined in the previous step (Fig. 21).

As explained in point 2.1.2, at the end of this step, the partial fire risk indices and the overall fire risk of the building are determined (Fig. 22).

Step 3 - Determination of the potential fire growth rate

At this stage, the potential fire growth rate is determined from the identification of the fire risk factors installed in the
Fig. 24 Analysis of risk factors for evacuation effects

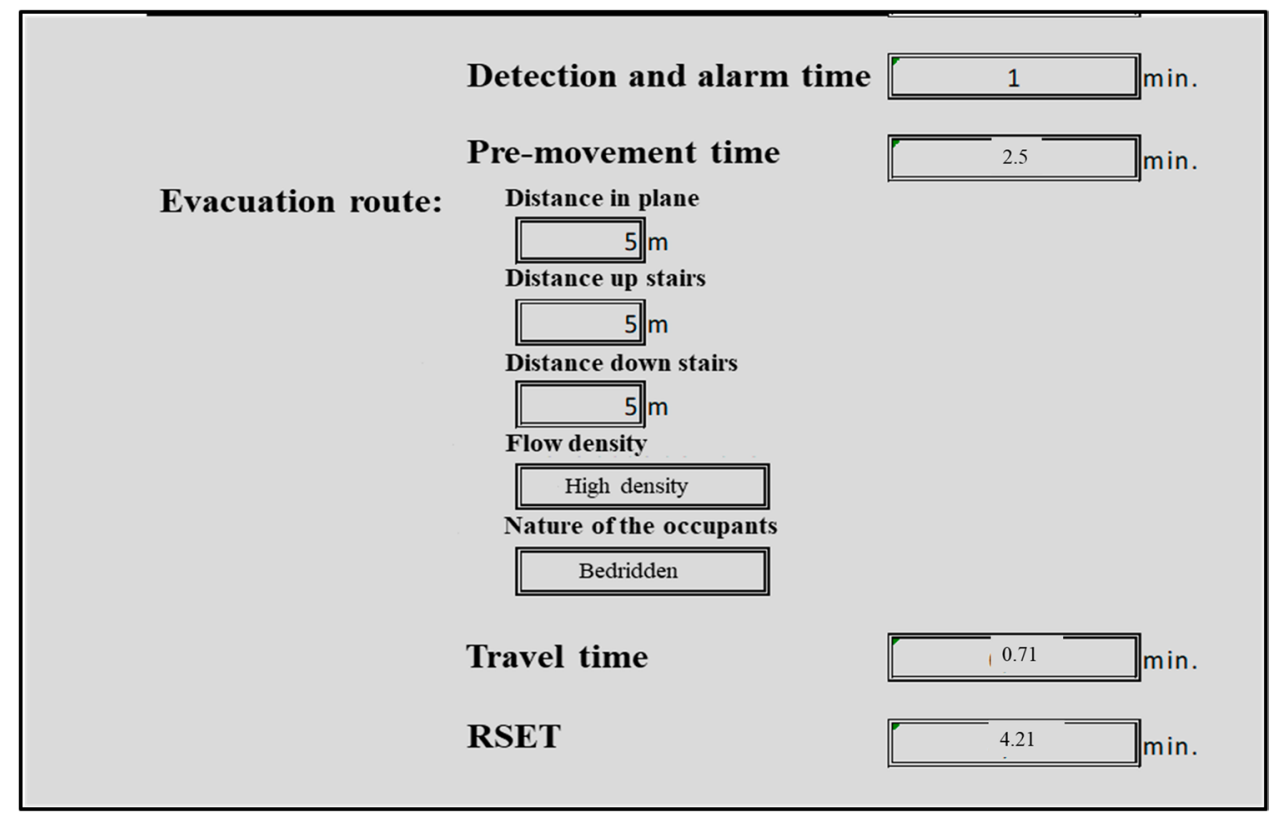


compartment of the fire outbreak, by systematic analysis of the combustible contents and the volumetric ratio of the compartment (Fig. 23).

Based on the potential fire growth rate, PEFIRA determines the Time Available for the safe evacuation of the building.

Step 4-Analysis of risk factors for evacuation purposes

In this step of applying the method, the risk factors relating to the evacuation process are analyzed, defined as alarm detection time, pre-movement time of occupants, distance to go from the most unfavorable point and time that can take to go through this distance, this time depending on any restrictions on perception and mobility of the occupants of the building (Fig. 24).

At the end of this step, the Time Required for the Safe Evacuation of the building (TNES) is determined.

Step 5-Analysis of building performance with fire scenarios

In this step, the building's performance and the consequent fire risk are analyzed based on fire scenarios, as explained in point 2.2. The critical fire scenario and the extreme scenario are also determined (Fig. 14) that serve to analyze and validate the performance of emergency response teams in the building (Fig. 25).

Step 6-Analysis of the performance and fire risk indicators

The developed model generates management indicators that allow a detailed "by layers" of the fire safety performance and the consequent fire risk of the building. This allows a micro and macro analysis of the performance of the critical components integrated in PEFIRA, which allows not only an effective fire risk assessment but also support the decision process in the context of the management of the fire safety system installed in the building (Fig. 26).

\section{Conclusions}

This paper presented the bases of a new performance-based fire risk analysis for buildings settled on a holistic approach of fire safety that allows a semi-quantitative fire risk assessment based on the potential of failure of components deemed indispensable. Comparing this methodology with other existing fire risk analysis methodologies, where there is a tendency for models predominantly based on prescriptive analysis and some on performance analysis, the proposed

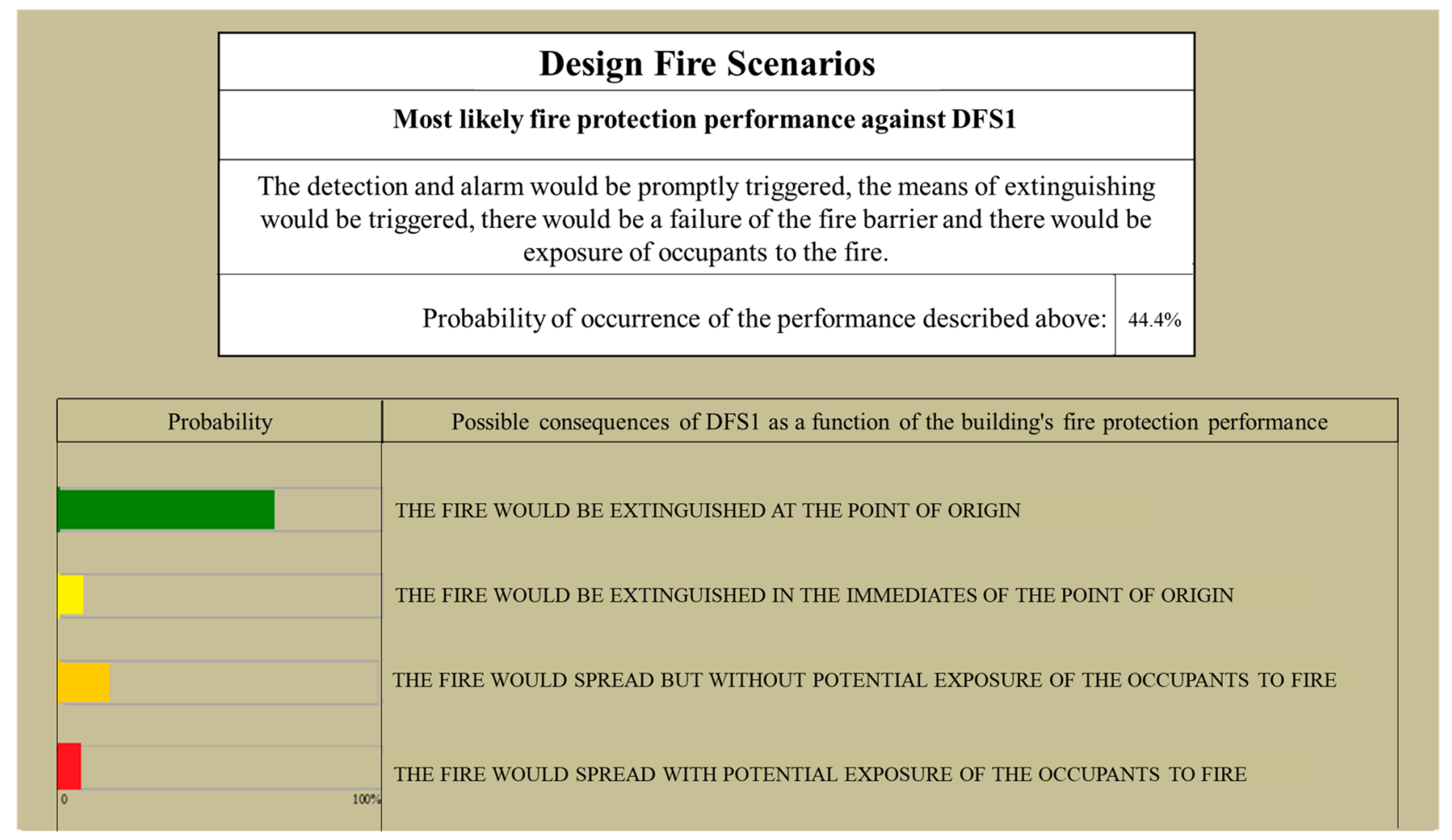

Fig. 25 - Indicators generated by PEFIRA in relation to building's performance against fire scenarios 
methodology, despite having a high number of components, is a combination of the two last approaches. Based on a redundant analysis that assesses the fire safety installed in the building and the consequent fire risk arising from its potential of failure, the methodology allows to assess the performance of buildings based in design fire scenarios. The fire risk assessment process integrates the three main dimensions that usually contribute to the analysis, namely the probability of the fire to occur, its severity and the subsequent possibility of people being exposed to fire. In order to reduce the degree of uncertainty of the assessment process, a priority analysis of the safety markers (PAI) is established, considering first order life-threatening PAI and second-order heritage PAI. This new methodology has i) a redundant

\section{PEFIRA}

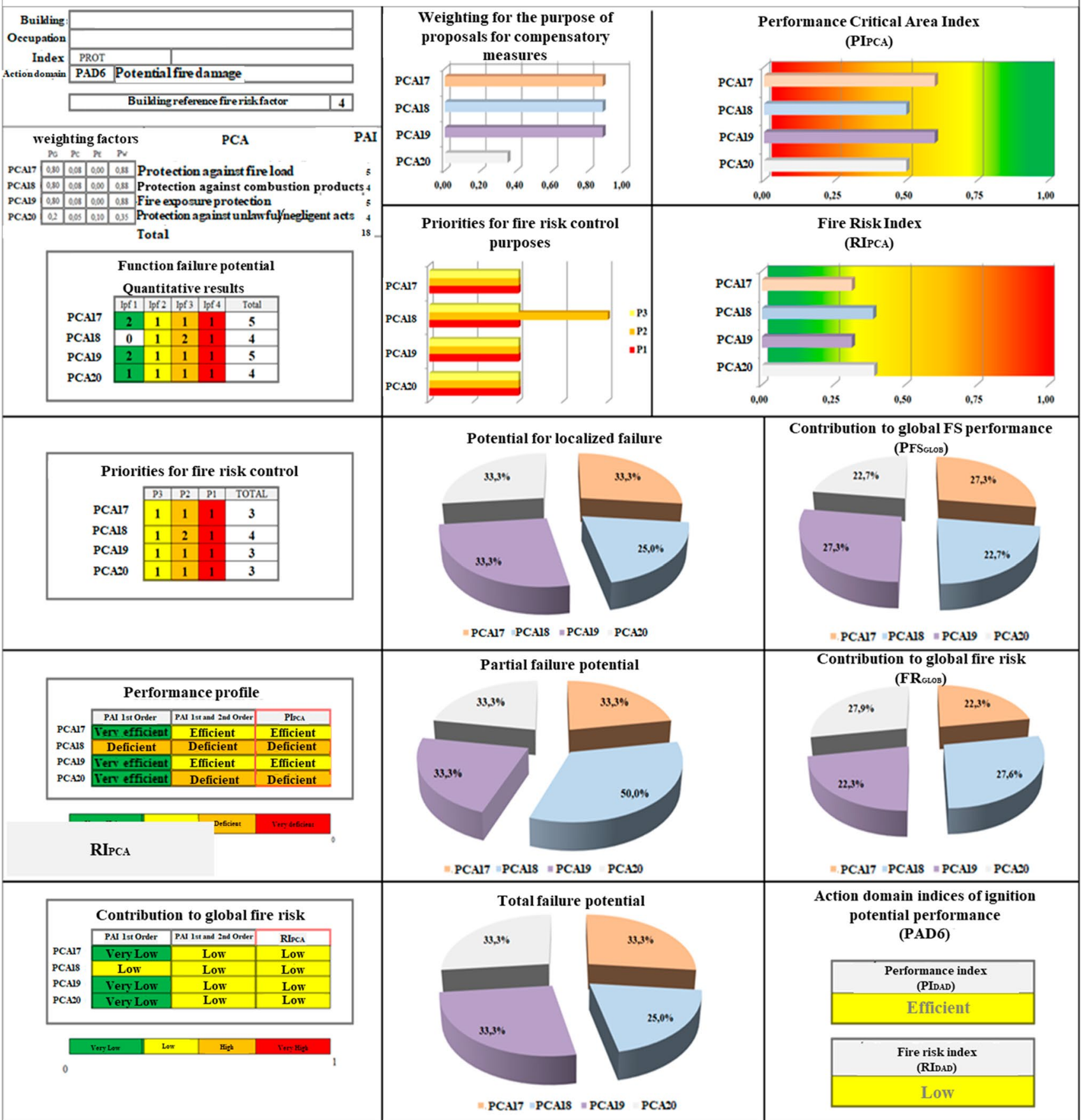

Fig. 26 - Example of indicators generated by PEFIRA regarding building performance 
estimation of the level of safety installed in the building and the consequent fire risk arising from its potential to failure as a function of reference performances and design fire scenarios; ii) a calculation of partial and global indicators that facilitate the identification of the fire safety system performance at the level of each fire safety component (micro analysis) and at the overall building level (macro analysis); iii) an enhanced use in multi-scenario context with a similar reliability of analysis due to a mathematical model that integrates fire risk correction factors at the level of the PAI and weighting factors at the level of the PCA; iv) a dynamic and integrated management of the fire safety system in buildings. This methodology considers the main assumptions for a fire risk analysis characterized in reliability, simplicity and multi-functionality.

The need for a broader and more repeated application of the methodology in a multi-scenario context remains open, with a view to its eventual refinement and thus demonstrating its operational consistency. The application of the methodology in field models will be presented in a following paper, allowing to verify its potential when compared to other fire risk assessment methodologies.

\section{Declarations}

Conflict of interest statement On behalf of all authors, the corresponding author states that there is no conflict of interest.

\section{References}

1. Watts JM, Hall JR (2016) Introduction to fire risk analysis, SFPE Handbook of Fire Protection Engineering, 5th edn. Springer, USA, pp 2817-2826

2. Frantzich H (1998) Risk analysis and fire safety engineering. Fire Safety Jornal 31(4):313-329

3. Meacham BJ (2004) Understanding risk: quantification, perception and characterization. J Fire Prot Eng 14:199-228

4. Martin M, Furness A (2007) Introduction to fire safety management. Elsevier, Oxford, p 440

5. Meacham BJ, Charters D, and Salisbury PJ (2015) Building fire risk analysis. SFPE handbook of fire protection engineering, 5th ed., Springer, USA, pp. 2941-2991.

6. Semit, E. D. (2007). FRAME, fire risk assessment method for engineering, France.

7. Fitzgerald RW, Meacham BJ (2017) Fire performance analysis for buildings, 2nd edn. Wiley, USA, p 640

8. NFPA 550 (2017) Guide to the fire safety concepts tree. National Fire Protection Association NFPA, USA, p 24

9. NFPA 101 (2018). Life safety code. National Fire Protection Association, Quincy, Massachusetts, USA, pp. 42-43.

10. Alexander D (2002) Principles of emergency planning and management. Terra Publishing, UK, p 379

11. Hadjisophocleous, G. and Zalok, E. (2004). Development of design fires for commercial buildings, Proc. Fire Safety Engineering International Conference 2004, Sydney AU, pp 1-14.
12. EN 1991-1-2 (2002): Eurocode 1: Actions on structures - Part 1-2: General actions - Actions on structures exposed to fire, European Committee for Standardization, Brussels, Belgium.

13. England JP, Young SA, Hui MC, Kurban N (2000) Guide for the design of fire resistant barriers and structures, Warrington Fire Research (Aust) Pty. Ltd. and Building Control Commission, Melbourne, Australia

14. Yung D (2008) Principles of fire risk assessment in buildings. Wiley, Toronto, Canada, p 227

15. Brannigan VM (2000). Fire scenarios or scenario fires? Can fire safety science provide the critical inputs for performance based fire safety analyses? Proceedings of the 6th International Symposium on Fire Safety. International Association for Fire Safety Science, France, pp. 207-218.

16. Society of Fire Protection Engineers (2007) Guide to performance-based fire protection. Society of Fire Protection Engineers and National Fire Protection Association, Quincy, MA, USA, p 207

17. Hurley, M. J. \& Bukowski, R. W. (2008). Fire hazard analysis techniques. fire protection handbook 20th, National Fire Protection Association, Quincy, MA, USA, pp. 121-134.

18. ICC (2005) International fire engineering guidelines. International Code Council, Washington, DC, p 415

19. Jutras I, Meacham BJ (2016) Development of objective-criteriascenario triplets and design fires for performance-based Fire Safety Design. Journal of Building Engineering 8:269-284

20. Mehaffey JR, Hadjisophocleous G (2016) Fire scenarios. SFPE Handbook of Fire Protection Engineering, 5th ed., Springer, USA, pp. $1262-1288$.

21. ISO 16733-1. (2015) Fire safety engineering - Selection of design fire scenarios and design fires - Part 1: Selection of design fire scenarios, International Organization for Standardization, Geneva, Switzerland, 31p.

22. Hadjisophocleous GV, Yung eD (1999) A description of the probabilistic and deterministic. International Journal on Engineering Performance-Based Fire Codes, pp.18-26.

23. Walton W, Thomas P (2002) Estimating temperatures in compartment fires. SFPE Handbook of Fire Protection Engineering, 3rd ed., P. J. DiNenno et al. (Eds.), National Fire Protection Association, Quincy, MA.

24. Coelho P, Costa EM (2007) Combustion. Ed. Orion, Amadora, Portugal, 374 p. (in Portuguese)

25. Frankel GJ (1993) Atmosferes rich in oxygen. Manual of Fire Protection. ed. MAPFRE. 2219 p..

26. NFPA 921 (2017) Guide for fire and explosion investigations. National Fire Protection Association, Quincy, MA, USA.

27. Tuve RL (1993) Principles of fire protection chemistry and physics. National Fire Protection Association, Quincy, MA, USA, $296 \mathrm{p}$

28. Della-Giustina DE (2014) Fire safety management handbook. CRC Press, 3rd ed., Morgantown, USA, 279 p.

29. Meignant A (2003) The management of the formation. Dom Quixote ed., Lisbon, Portugal, 300 p. (in Portuguese).

30. Buckley R, Caple eJ (2009) One-to-one training and coaching skills. Kogan Page, London, UK

31. Grau VP (2003) Fire dynamics - origin of the fires. ed. del Bullent, Valencia, Spain, 381 p. (in Spanish)

32. Real PV (2003) Fire in steel structures: structural, Design. Orion, Amadora, Portugal ((in Portuguese))

33. Kawagoe K (2004) Fire behavior in rooms. J Fire Prot Eng 14:5-8

34. Henriques PDF (2010) Fire behaviour of structural glass. Masters Thesis in Civil Engineering, University of Aveiro, Portugal (in Portuguese).

35. Harmathy TZ (1985) Fire safety science and engineering. American Society for Testing and Materials (ASTM), STP882, Philadelphia, USA, 427 p.. 
36. Tien CL, Lee KY, Stretton AJ (2016) Radiation heat transfer. SFPE Handbook of Fire Protection Engineering, 5th ed., Springer, USA, pp. 102-137.

37. Beyler CL, Shokri M (1989) Radiation from larger pool fires. J Fire Prot Eng 1(4):141-149

38. Center for Chemical Process Safety (2012) Guidelines for fire protection in chemical, petrochemical, and hydrocarbon processing facilities. Wiley, USA, p 483

39. Wieczorek CJ, Dembsey NA (2016) Effects of thermal radiation on people: predicting 1st and 2nd Degree Skin Burns. SFPE Handbook of Fire Protection Engineering, 5th ed., Springer, USA, pp 2705-2737
40. US Fire Administration (2017) Fire in the United States 20062015. Federal Emergency Management Agency (FEMA), 19th ed., 95 p..

41. Tubbs J, Meacham BJ (2007) Egress design solutions: a guide to evacuation and crowd management planning. Wiley, USA, p 544p

42. International Fire Service Training Association (2013) Essentials of fire fighting and fire department operations. Oklahoma, USA, 6th ed..

43. Fagel MJ (2014) Crisis management and emergency planning: preparing for today's challenges. CRC press, 550p.

44. Alexander D (2002) Principles of emergency planning and management. Terra Publishing, UK, p 379p 